Article

\title{
An Evaluation of Image Velocimetry Techniques under Low Flow Conditions and High Seeding Densities Using Unmanned Aerial Systems
}

\author{
Sophie Pearce ${ }^{1, *}$, Robert Ljubičić ${ }^{2}(0)$, Salvador Peña-Haro ${ }^{3}$, Matthew Perks ${ }^{4}$, Flavia Tauro ${ }^{5}$, \\ Alonso Pizarro ${ }^{6}$ (D), Silvano Fortunato Dal Sasso ${ }^{7}$, Dariia Strelnikova ${ }^{8}$, Salvatore Grimaldi ${ }^{5}$, \\ Ian Maddock ${ }^{1}$, Gernot Paulus ${ }^{8}$ (D), Jasna Plavšić ${ }^{2} \mathbb{D}$, Dušan Prodanović ${ }^{2} \mathbb{D}$ and Salvatore \\ Manfreda 9 (D) \\ 1 School of Science and the Environment, University of Worcester, Worcester WR2 6AJ, UK; \\ i.maddock@worc.ac.uk \\ 2 The Faculty of Civil Engineering, University of Belgrade, Belgrade 11120, Serbia; rljubicic@grf.bg.ac.rs (R.L.); \\ jplavsic@grf.bg.ac.rs (J.P.); dprodanovic@grf.bg.ac.rs (D.P.) \\ 3 Photrack AG: Flow Measurements, Ankerstrasse 16a, 8004 Zurich, Switzerland; pena@photrack.ch \\ 4 School of Geography, Politics and Sociology, Newcastle University, Newcastle upon Tyne NE1 7RU, UK; \\ Matthew.Perks@newcastle.ac.uk \\ 5 Department for Innovation in Biological, Agro-Food and Forest Systems, University of Tuscia, 01100 Viterbo, \\ Italy; flavia.tauro@unitus.it (F.T.); salvatore.grimaldi@unitus.it (S.G.) \\ 6 Department of European and Mediterranean Cultures: Architecture, \\ Environment and Cultural Heritage (DICEM), University of Basilicata, 75100 Matera, Italy; \\ alonso.pizarro@unibas.it \\ 7 Consortium of Italian Universities for Hydrology (CINID), 85100 Potenza, Italy; silvano.dalsasso@cinid.it \\ 8 School of Geoinformation, Carinthia University of Applied Sciences, 9524 Villach, Austria; \\ d.strelnikova@fh-kaernten.at (D.S.); g.paulus@fh-kaernten.at (G.P.) \\ 9 Department of Civil, Architectural and Environmental Engineering, University of Naples Federico II, \\ via Claudio 21, 80125 Napoli, Italy; Salvatore.manfreda@unibas.it \\ * Correspondence: g.pearce@worc.ac.uk
}

Received: 17 December 2019; Accepted: 6 January 2020; Published: 9 January 2020

check for updates

\begin{abstract}
Image velocimetry has proven to be a promising technique for monitoring river flows using remotely operated platforms such as Unmanned Aerial Systems (UAS). However, the application of various image velocimetry algorithms has not been extensively assessed. Therefore, a sensitivity analysis has been conducted on five different image velocimetry algorithms including Large Scale Particle Image Velocimetry (LSPIV), Large-Scale Particle Tracking Velocimetry (LSPTV), Kanade-Lucas Tomasi Image Velocimetry (KLT-IV or KLT), Optical Tracking Velocimetry (OTV) and Surface Structure Image Velocimetry (SSIV), during low river flow conditions (average surface velocities of $0.12-0.14 \mathrm{~m} \mathrm{~s}^{-1}$, Q60) on the River Kolubara, Central Serbia. A DJI Phantom 4 Pro UAS was used to collect two 30-second videos of the surface flow. Artificial seeding material was distributed homogeneously across the rivers surface, to enhance the conditions for image velocimetry techniques. The sensitivity analysis was performed on comparable parameters between the different algorithms, including the particle identification area parameters (such as Interrogation Area (LSPIV, LSPTV and SSIV), Block Size (KLT-IV) and Trajectory Length (OTV)) and the feature extraction rate. Results highlighted that KLT and SSIV were sensitive to changing the feature extraction rate; however, changing the particle identification area did not affect the surface velocity results significantly. OTV and LSPTV, on the other hand, highlighted that changing the particle identification area presented higher variability in the results, while changing the feature extraction rate did not affect the surface velocity outputs. LSPIV proved to be sensitive to changing both the feature extraction rate and the particle identification area. This analysis has led to the conclusions that for surface velocities of approximately $0.12 \mathrm{~m} \mathrm{~s}^{-1}$ image velocimetry techniques can provide results comparable
\end{abstract}


to traditional techniques such as ADCPs. However, LSPIV, LSPTV and OTV require additional effort for calibration and selecting the appropriate parameters when compared to KLT-IV and SSIV. Despite the varying levels of sensitivity of each algorithm to changing parameters, all configuration image velocimetry algorithms provided results that were within $0.05 \mathrm{~m} \mathrm{~s}^{-1}$ of the ADCP measurements, on average.

Keywords: image velocimetry; UAS; river flow monitoring; LSPIV; LSPTV; KLT; OTV; SSIV; surface flow velocity

\section{Introduction}

Monitoring river flow (discharge) is essential for the development of river science research and management [1]. A critical component of computing river flow is velocity. This is achieved through using in situ velocity measurement tools such as current meters, acoustic Doppler current profilers (ADCPs) and ultrasonic gauges [2]. Such measurements typically use the velocity-area method to calculate discharge [3]. Periodic gaugings are commonly conducted across the observed flow range, up to bankfull conditions, or up to the point where hydrological conditions prevent access/accurate measurements to be obtained [2]. Determination of flow beyond the gauged maxima typically relies on an extrapolated stage-discharge relationship $[4,5]$. This often leads to unquantified uncertainty in flow predictions. Therefore, innovative techniques for monitoring river flow has increased in the past decade to facilitate the measurement of challenging flows (usually flood conditions). However, the use of remote flow monitoring methods could be useful for monitoring a range of river flows [6-8].

Various remote flow monitoring techniques have been introduced in recent years, including the use of radars [4] and the use of terrestrial and airborne camera sensors [5,9,10]. The use of cameras for monitoring river flow has been used through a technique known as image velocimetry. Large-Scale Particle Image Velocimetry (LSPIV), the first image velocimetry technique to be introduced in outdoor environments, was originally developed by Fujita (1997) which applies the principles of the classic Particle Image Velocimetry (PIV) techniques to fluvial field conditions (large-scale) [11]. Image velocimetry has been successfully used to monitor river flow in many different applications, for example, crowd sourced data has been used to calculate the flow of a flash flood in the French Alps [1], 2D flow fields have been assessed for hydraulic engineering applications [12], and discharges flowing through a broken embankment during a large snow-melt flood in Japan have been calculated [13]. Since the introduction of LSPIV, various other algorithms have been developed which adopt alternative approaches for the calculation of surface flow velocity (Table 1). Image velocimetry algorithms commonly used are: Large-Scale Particle Image Velocimetry (LSPIV) [14,15], Large-Scale Particle Tracking Velocimetry (LSPTV) [16,17], Surface Structure Image Velocimetry (SSIV) [18], Optical Tracking Velocimetry (OTV) [19] and Kanade-Lucas Tomasi Image Velocimetry (KLT-IV or KLT) [20]. An overview of each of these algorithms is described in Table 1.

Traditionally, image velocimetry techniques applied within fluvial field environments have used handheld cameras, elevated and angled towards to the water's free surface. For example, cameras can be mounted on bridges [5,10], buildings [21] or attached to telescopic poles [22]. The camera platform records the water's surface, and image velocimetry algorithms use information present on the free surface to generate velocity estimates. Unmanned Aerial Systems (UAS) have been increasingly used for the calculation of surface flow velocities [23], as they offer many advantages over bankside, oblique cameras. For example, during events such as flash-floods, where traditional techniques would be unsafe or impractical to deploy, a UAS could be deployed rapidly and a flow measurement can be collected in minutes, without pre-flight calibrations [20]. Furthermore, UAS may be used to record from a nadir perspective which reduces camera distortions and reduces complexity related to image pre-processing. Oblique bankside cameras require a high degree of transformations to reduce 
camera distortions which can negatively influence the velocimetry accuracy, particularly in low flows. Moreover, avoiding transformations where possible (using UAS) can reduce the computational time and potential errors associated with image transformations during the pre-processing phase [23].

Table 1. Brief overview of the image velocimetry techniques applied throughout this research.

\begin{tabular}{|c|c|c|c|}
\hline $\begin{array}{l}\text { Image Velocimetry } \\
\text { Algorithm }\end{array}$ & Brief Overview of Technique & Requirements & Advantages \\
\hline $\begin{array}{l}\text { Kanade-Lucas Tomasi } \\
\text { Image Velocimetry } \\
\text { (KLT-IV) Processed } \\
\text { using KLT-IV developed } \\
\text { by Matthew Perks [20] }\end{array}$ & $\begin{array}{l}\text { KLT uses spatial intensity information to detect and } \\
\text { search for the position that yields the best match. } \\
\text { The KLT-IV process begins with the creation of a } \\
\text { camera model, using the cameras internal parameters } \\
\text { and Ground Control Points (GCPs). The KLT } \\
\text { algorithm is then applied to detect the movement of } \\
\text { GCPs within the field of view and images are } \\
\text { stabilized using this information. Once images are } \\
\text { stabilized, the KLT algorithm is applied to the water } \\
\text { surface, and surface features are tracked for the } \\
\text { calculation of surface flow velocity. (See [20]). }\end{array}$ & $\begin{array}{l}\text { The camera parameters } \\
\text { are required for correct } \\
\text { creation of a camera model } \\
\text { for calibration and } \\
\text { orthorectification of } \\
\text { imagery. The duration } \\
\text { over which individual } \\
\text { trajectories are tracked } \\
\text { (the extraction rate) and } \\
\text { the block size are required. }\end{array}$ & $\begin{array}{l}\text { Works well in } \\
\text { conditions where } \\
\text { surface features are } \\
\text { sparse and works } \\
\text { well in } \\
\text { unsteady flows. }\end{array}$ \\
\hline $\begin{array}{l}\text { Large-Scale Particle } \\
\text { Image Velocimetry } \\
\text { (LSPIV) Processed in } \\
\text { PIVlab developed by [24] }\end{array}$ & $\begin{array}{l}\text { LSPIV uses a classical cross-correlation algorithm } \\
\text { which is applied to pairs of orthorectified (distortion } \\
\text { corrected) images, separated by a given time interval. } \\
\text { Interrogation areas and search areas are defined by the } \\
\text { user, and the most likely displacement of surface } \\
\text { patterns is calculated between the interrogation area in } \\
\text { frame one and the search area in frame } 2 \text {. The most } \\
\text { likely displacement of visible tracers is determined as } \\
\text { the maximum cross-correlation coefficient, and is used } \\
\text { for the calculation of instantaneous velocity flow field. } \\
\text { (See [5]). }\end{array}$ & $\begin{array}{l}\text { Sufficient seeding density } \\
\text { is required across the } \\
\text { entire field of view for } \\
\text { accurate surface velocity } \\
\text { calculations. The } \\
\text { interrogation area and } \\
\text { search area sizes need to } \\
\text { be defined by the user. }\end{array}$ & $\begin{array}{l}\text { Can provide full } \\
\text { surface flow } \\
\text { velocity maps. } \\
\text { LSPIV is the most } \\
\text { tested technique } \\
\text { and therefore the } \\
\text { most adopted } \\
\text { to date. }\end{array}$ \\
\hline $\begin{array}{l}\text { Large-Scale Particle } \\
\text { Tracking Velocimetry } \\
\text { (LSPTV) Processed } \\
\text { using PTVlab developed } \\
\text { by Antoine Patalano }\end{array}$ & $\begin{array}{l}\text { LSPTV consists of particle identification and tracking. } \\
\text { Images are processed to enhance the appearance of } \\
\text { particles in the field of view, and the location of the } \\
\text { centroid of the particles in frames is recovered. In the } \\
\text { tracking phase, the centroid of the detected particles is } \\
\text { identified in subsequent images to reconstruct the } \\
\text { particle trajectory (See [16]). }\end{array}$ & $\begin{array}{l}\text { The size and shape of the } \\
\text { particles must be known. } \\
\text { However, LSPTV can } \\
\text { work accurately with few } \\
\text { particles distributed } \\
\text { throughout the field of } \\
\text { view. The interrogation } \\
\text { area size needs to be } \\
\text { defined by the user. }\end{array}$ & $\begin{array}{l}\text { Works well in } \\
\text { conditions where } \\
\text { surface features are } \\
\text { sparse and works } \\
\text { well in unsteady } \\
\text { flows [25] }\end{array}$ \\
\hline $\begin{array}{c}\text { Optical Tracking } \\
\text { Velocimetry (OTV) } \\
\text { Processed using OTV } \\
\text { algorithm developed } \\
\text { by [19] }\end{array}$ & $\begin{array}{l}\text { The OTV approach combines automated feature } \\
\text { detection, tracking through the Lucas-Kanade } \\
\text { algorithm, and trajectory-based filtering that retain the } \\
\text { most realistic trajectories which pertain to objects in } \\
\text { the field of view. Features such as corners and } \\
\text { junctions are detected through the Fast from } \\
\text { Accelerated Segment Test (FAST) algorithm. Such } \\
\text { features are then tracked with the pyramidal } \\
\text { Lucas-Kanade sparse first-order differential technique. } \\
\text { Images are sub-sampled up to four levels with a } \\
\text { search window down to } 15 \times 15 \text { pixels in size. Out of } \\
\text { all trajectories, only those which exhibit a minimum } \\
\text { length and inclination with respect to the stream } \\
\text { cross-section are retained for further processing. } \\
\text { The length and angle of the trajectories can be selected } \\
\text { by the user. }\end{array}$ & $\begin{array}{l}\text { OTV does not rely on the } \\
\text { deployment of tracers in } \\
\text { the field of view. } \\
\text { The length and angle of } \\
\text { the trajectory needs to be } \\
\text { defined by the user, } \\
\text { as well as the maximum } \\
\text { number of trajectories. }\end{array}$ & $\begin{array}{l}\text { Works well in } \\
\text { conditions where } \\
\text { surface features are } \\
\text { sparse, and where } \\
\text { flows are unsteady }\end{array}$ \\
\hline $\begin{array}{l}\text { Surface Structure } \\
\text { Image Velocimetry } \\
\text { (SSIV). } \\
\text { Processed using SSIV } \\
\text { algorithm developed } \\
\text { by photrack } \\
\text { (photrack.ch) [18] }\end{array}$ & $\begin{array}{l}\text { SSIV is a development of LSPIV which uses a similar } \\
\text { cross-correlation algorithms for the calculation of } \\
\text { surface flow. However, SSIV was developed to } \\
\text { overcome some of the factors which make LSPIV } \\
\text { susceptible to errors. SSIV introduces a filter which } \\
\text { mitigates the effects of shadows and glare, as well as } \\
\text { the need for a densely seeded flow surface. } \\
\text { Furthermore, a camera model is introduced for the } \\
\text { orthorectification of imagery and surface velocity } \\
\text { calculation (See [18]). }\end{array}$ & $\begin{array}{l}\text { The camera parameters } \\
\text { are required for correct } \\
\text { creation of a camera model } \\
\text { for calibration and } \\
\text { orthorectification of } \\
\text { imagery. The interrogation } \\
\text { area and search area sizes } \\
\text { need to be defined by } \\
\text { the user. }\end{array}$ & $\begin{array}{l}\text { Can provide full } \\
\text { surface flow } \\
\text { velocity maps } \\
\text { within deteriorated } \\
\text { image conditions } \\
\text { (shadows or glares } \\
\text { on the water } \\
\text { surface, as well as } \\
\text { in poor light } \\
\text { conditions). }\end{array}$ \\
\hline
\end{tabular}

The methodology of image velocimetry can be described in four main stages: (i) image acquisition, (ii) image pre-processing, (iii) image analysis and (iv) image post-processing. Image acquisition is the most straightforward stage of the process when videos (or image sequences recorded at a known time interval) of the river's surface are recorded. For most algorithms it is also necessary for the river to have 
features present on the water surface $[5,26]$ (see Table 1 for the specific requirements of each algorithm). Surface features, often referred to as 'seeding', can be naturally occurring features on a river's surface such as boils, ripples or debris [5]. If features are not naturally occurring then environmentally friendly, inert and biodegradable artificial seeding material such as ecofoam or wood chippings/mulch or any object that is naturally buoyant can be added to the river channel [27]. The pre-processing phase includes, when necessary, image orthorectification, removal of lens distortions, and image stabilization [25]. Often the pre-processing stage will also include applying various filters or corrections to the imagery in order to enhance the appearance of seeding particles, or removing shadows or glares that can affect the quality of image velocimetry results [18]. Post-processing usually aims to remove any spurious vectors or results within the results calculated; however, this stage is not always conducted on all algorithms. Typically, stages (i) and (ii) are similar for all image velocimetry algorithms.

All image velocimetry algorithms inherently work differently. However, commonly certain parameters need to be defined for each algorithm before image velocimetry analysis can be conducted (Table 1). Usually, such parameters are associated with particle identification for the tracking phase to be computed successfully. For LSPIV the particle identification parameters are known as Interrogation Areas (IA) and Search Areas (SA). IAs are areas of defined size (in pixels) and are used to identify patterns on the water surface, which are to be searched for in the second image, throughout the region of the designated SA. This process is computed for all frames, within a defined region of interest. The size of the IA and SA are user defined, and will vary depending on the conditions of sampling (i.e., the acquisition frame rate, the flow rate and the density and distribution of surface features). Particle identification within SSIV and LSPTV is similar to that of LSPIV in that an IA needs to be defined. However, in LSPTV the size and shape of the particles need to be defined before the size of the IA is chosen. The IA is then used to track individual particles, throughout the sequence of frames. For KLT-IV, a particle identification area does not need to be specified. KLT works by iteratively tracking features present on the water's surface. However, a 'block size' variable defines the size of the search neighborhood around each point being tracked [20]. In contrast to other approaches, OTV implements feature identification, tracking through the Lucas-Kanade algorithm, and trajectory-based filtering. Out of all trajectories, only those that exhibit minimum length and direction with respect to the stream cross-section are retained for further processing. The threshold length and angle of the trajectories can be selected by the user. Throughout this analysis, these parameters will be referred to as 'particle identification and search area/lengths' for all algorithms.

Sutarto [28] conducted an analysis on the influence of the IA and SA for LSPIV analysis. This analysis provided a robust overview of the sensitivity of LSPIV to changing the IA and SA within one set of flow conditions, while keeping all other parameters consistent. It has previously been suggested that for LSPIV the IA should be large enough to encounter sufficient density of particles for cross-correlation, but small enough to avoid ambiguous results [25,27]. For LSPIV, SSIV and LSPTV there is a direct relationship between the size of the particle identification area and the sampling frequency (frame rate/feature extraction rate) [29]. For example, if the frame-by-frame displacement of particles is larger than the size of the particle identification area, then it is most likely that particles/patterns on the water surface will not be detected accurately [15]. For KLT-IV, the sensitivity of the feature extraction rate, and the search areas/lengths has yet to be tested extensively [20], while for OTV, the sensitivity of the trajectory length is yet to be explored [19].

It is well known that for LSPIV and LSPTV it is necessary to identify the optimal sampling frequency (tracked feature extraction rate) in relation to the conditions being sampled [16]. For example, during high velocities a high sampling frequency is required to avoid the loss of detected particles and thus a loss in measurement accuracy [27], furthermore, particle deformation may be induced by the particle movement and camera settings [16]. Most camera sensors will typically record videos at a given frequency of 24, 30 or 60 frames per second (fps). However, often with image velocimetry it is necessary to alter the sampling frequency rate to provide a suitable displacement of particles between image pairs, especially during low flow conditions when the displacement of particles between frames 
will be naturally very small [26]. Tauro et al. [19] analyzed the sensitivity of OTV to changing the frequency of the feature extraction rate, and concluded that for OTV average velocities obtained with varying frequencies (from $25 \mathrm{~Hz}$ down to $7-8 \mathrm{~Hz}$ ) showed no statistical significance, and therefore in the conditions recorded (average $0.47 \mathrm{~m} \mathrm{~s}^{-1}$ ) OTV was not sensitive to feature extraction rate frequencies. Finally, KLT-IV has been developed to operate at the feature extraction rate that the images were acquired. It can detect and tracking individual features across a sequence of images collected at high frame rates (i.e., $>30 \mathrm{fps}$ ). However, the impact of the duration over which the features are tracked on the calculated displacement rates has yet to be assessed.

One of the main challenges regarding the processing of image velocimetry is the need for the user to define the particle identification and search area/length and frame extraction rate. Because the particle identification area depends on a multitude of factors such as the flow rate, the frame rate and seeding density (in LSPIV), it becomes challenging for inexperienced users to decide on the appropriate parameters, and can therefore lead to the inaccurate calculation of the surface flow velocity [22]. Very little research to date has focused on comparing the sensitivity of the particle identification and search areas/lengths and feature extraction rates to various algorithms within one set of environmental conditions.

The goal of this research is to examine the application of five different image velocimetry algorithms (i.e., KLT, LSPIV, LSPTV, OTV and SSIV) during low flow conditions. In particular, the research aims to evaluate the parameter sensitivity of the algorithms by examining the influence of changing feature extraction rates, particle identification and search area/lengths on the estimated flow velocities. Furthermore, the research analyses the consistency of estimated velocities with the reference data obtained with an acoustic Doppler current profiler (ADCP). Given that different algorithms are likely to perform best under alternative flow conditions, and since some of the algorithms may require additional steps (e.g., image pre-processing) in order to demonstrate their best performance, it is beyond the scope of this research to provide an assessment of which algorithm performs the best overall.

\section{Methodology}

\subsection{Study Site}

Fieldwork was carried out on Kolubara River near the city of Obrenovac in Central Serbia (Figure 1). The selected river reach is in the approximate center of a left-to-right ogee bend which forms a characteristic ridge structure on the riverbed due to sediment deposition (Figure 2). Both banks in the region of interest (ROI) are stone-in-mortar fortifications, while the riverbed is natural sediment. Cross-sectional surface width was relatively constant, varying between 23.30 and $23.45 \mathrm{~m}$. During the experiment, low flow conditions were present with a discharge of approx. $3.4 \mathrm{~m}^{3} \mathrm{~s}^{-1}$ (estimated using $\mathrm{ADCP}$ ) (Q60, calculated from monthly flow data), and depths of up to $1.9 \mathrm{~m}$. Although no detailed examination of the water properties was conducted, it is estimated that the turbidity of the water was moderate, as the riverbed was visible in low-depth regions of the reach $(>0.5 \mathrm{~m})$. Moving bed tests carried out with the ADCP showed no significant bed movement during the experiment. Four-beam bottom-tracking data was used for bathymetry purposes, since the characteristics of the soft bed sediment prevented single vertical-beam data to obtain reliable readings across the entire reach.

\subsection{Experimental Data Acquisition and Data Treatment}

\subsubsection{ADCP Processing}

River flow and bathymetry data was acquired using SonTek RiverSurveyor M9 [30], in a total of three cross-sections, with 2-6 ADCP transects in each section. The RiverSurveyor was mounted on a tethered boat, which was in turn pulled manually from one bank to the other. Boat velocity was kept below the rivers surface flow velocity at all times, and boat track was kept as perpendicular to the flow 
direction as possible. Transducer immersion depth was estimated in situ as $0.10 \mathrm{~m}$, while its screening distance was set to $0.06 \mathrm{~m}$. The bottom $10 \%$ of the recorded profile was discarded due to the expected side-lobe interference with the main beam near the riverbed. For discharge estimation, missing top and bottom subsections of the velocity profiles were estimated using power fit method [31]. Cell size in the velocity profile depends on the frequency of the ADCP transducer. RiverSurveyor M9 offers two sets of four transducers (Janus configuration) for velocity estimation-1 $\mathrm{MHz}$ transducers which form cells of $6 \mathrm{~cm}$ in height, and $3 \mathrm{MHz}$ transducers which form $2 \mathrm{~cm}$ cells. The device automatically switched from one transducer set to the other based on the available sample depth-lower frequency $(1 \mathrm{MHz})$ for higher depths and vice versa. Number of cells varied from 10 to 65 depending on the sample. Following the USGS guidelines [32], the mean discharge was estimated at $3.4 \mathrm{~m}^{3} \mathrm{~s}^{-1}$. For each of the cross-sections in the ROI, one representative transect was chosen for UAS benchmarking based on the following criteria: (1) number of available samples (ensembles) in a transect, (2) number of valid samples, (3) number of invalid bins, (4) presence of noise, and (5) ratio of measured/total discharge. The proximity of the bridge rendered the use of the onboard GPS impossible, so bottom-tracking data was used instead, along with other in situ notes and measurements. This procedure allowed the merging of bottom-track co-ordinates from individual transects into one georeferenced dataset. A portion of points closest to the channel edges were discarded due to spurious results caused by low-depth side-lobe interference [31]. It is also likely that the ADCP would produce a bias towards higher velocity magnitudes near high-slope channel edges, due to interference of signal from shallow, low-velocity zone, with high velocity signal from deeper zone towards the center of the channel (Figure 3). It should be noted that the variability of ADCP-measured velocities is significantly higher for low-velocity conditions (12\%), with average flow velocity below $0.25 \mathrm{~m} \mathrm{~s}^{-1}$, than for higher velocity flow $(2.5 \%,[33])$. The ADCP is unable to directly record the surface velocities due to the submergence of the transducer and its blanking distance. Estimation of surface velocity in each sample was based on the later analyses of velocity data from individual bins. This way, characteristic velocity depth profiles can be extrapolated to estimate the surface velocities.
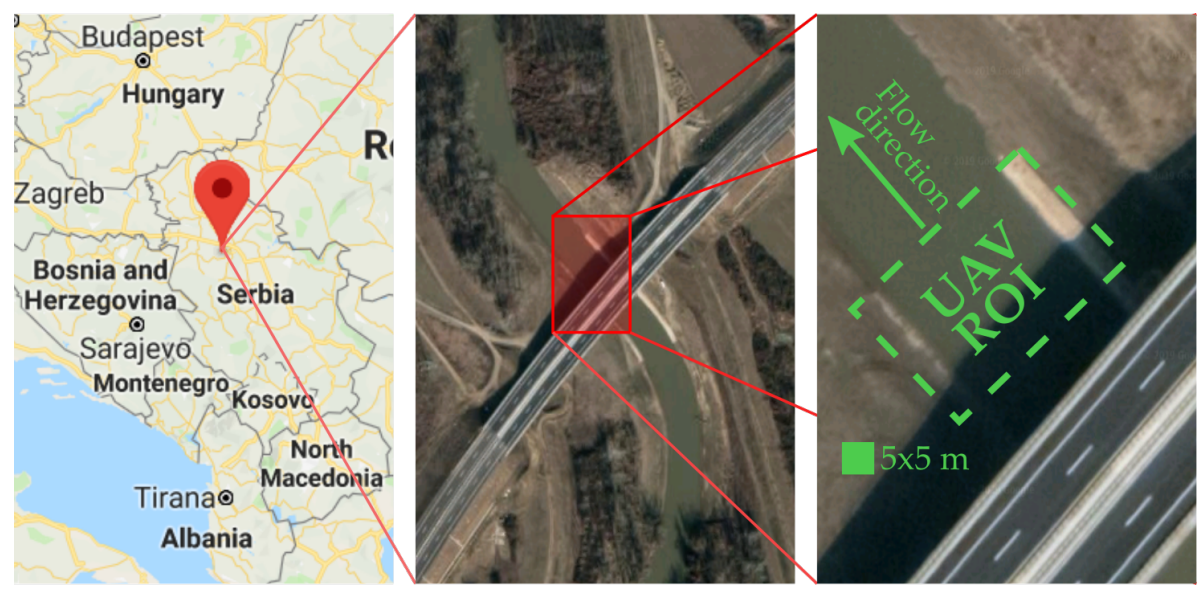

Figure 1. Location and satellite imagery of the study site and Region of Interest (ROI), (C) Google Maps 2019. 


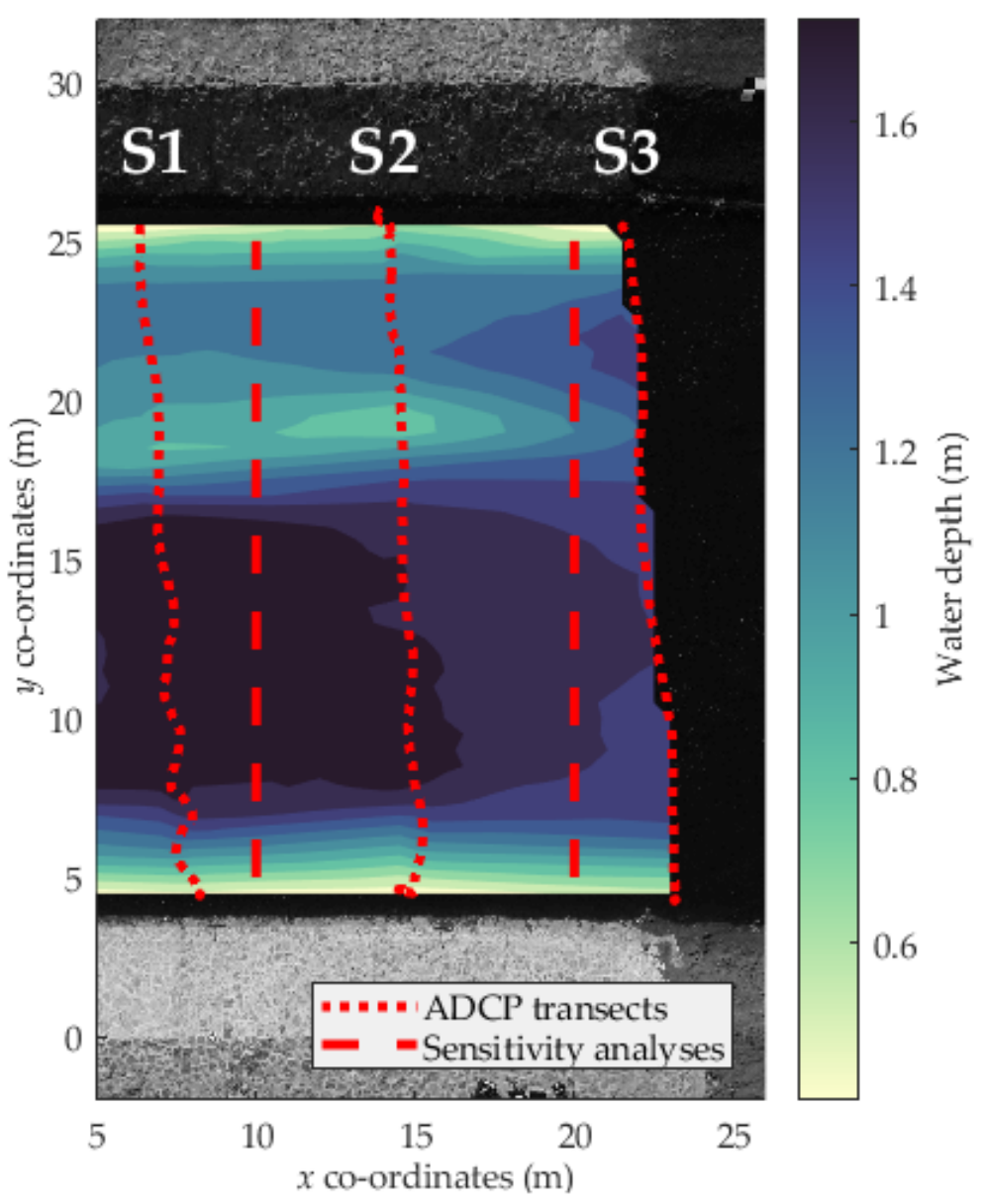

Figure 2. Bathymetry profile of the Region of Interest, including the locations of ADCP transects (from left to right: S1, S2 and S3), and sensitivity analysis transects (from left to right cross-section $10 \mathrm{~m}$ and $20 \mathrm{~m})$.

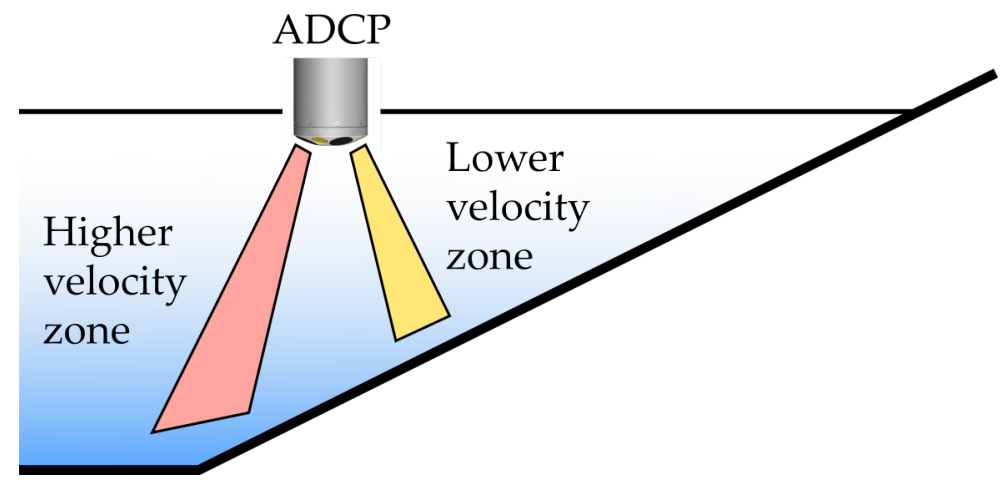

Figure 3. Signal interference near high-slope channel edges.

\subsubsection{Image Processing}

The UAS platform used for data acquisition was the DJI Phantom 4 Pro, mounted with the standard fitted camera sensor (1" CMOS 20MP). The inbuilt triaxial gimbal allows for compensating the UAS vibrations and reduces potential distortions in the video. In order to establish suitable seeding conditions for image velocimetry purposes, red wooden mulch was thrown by-hand (by multiple people, simultaneously) from a bridge just upstream of the selected reach. Seeding particles were irregularly shaped and on average $6 \times 6$ pixels $(6 \times 6 \mathrm{~cm})$ in size. The experiment was conducted sequentially, UAS surveys were completed first, including the distribution of seeding material. Then, three ADCP cross-sections were obtained after the UAS surveys as to not to disturb the UAS recording 
and the tracers/surface velocity field. The time between the measurements was minimal, and the stage was constant throughout, thus it is likely discharges remained stable throughout the experiment. For UAS orthorectification and video stabilization purposes, six Ground Control Points (GCPs) were positioned along the riverbanks, three on each side. Two sizes of chequered-pattern GCPs were used: (1) $65 \times 65 \mathrm{~cm}$ and (2) $20 \times 20 \mathrm{~cm}$. Distances between individual GCPs were measured using a laser distance meter, and the spatial layout of the GCP network was determined using least square adjustment method [34].

Here we present a subset of a $5 \mathrm{~min} 27 \mathrm{~s}$ video that was collected during the field campaign. The video was recorded at a resolution of $4 \mathrm{k}(4096 \times 2160$ pixels), and a frame rate of 23.98 frames per second (fps) using the standard fitted DJI Phantom 4 Pro camera. Two videos of $30 \mathrm{~s}$ were sub-sampled from the original video and were chosen according to their length of stability without sudden camera movements. Video A was recorded at an altitude of $26 \mathrm{~m}$ above the water surface and has a ground sampling distance of $0.77 \mathrm{~cm} / \mathrm{px}$. Video B was recorded at $32 \mathrm{~m}$ above the water surface and has a ground sampling distance of $0.95 \mathrm{~cm} / \mathrm{px}$. Both videos were recorded with a camera angle of approx. 5 degrees from nadir. For Video A and Video B, the average seeding densities were $5.93 \times 10^{-4}$ and $4.73 \times 10^{-4}$ particles per pixel (ppp), respectively.

Videos and GCP data were imported into KLT-IV and orthorectified using information on the internal camera parameters (e.g., focal length, radial and tangential distortion coefficients), and the known locations of six GCPs. Although the gimbal axis compensates for UAS vibrations, the UAS camera platform is still susceptible to movement due to wind effects, with an approximate displacement of 33 pixels, for this dataset. Therefore, the videos have also been stabilized by using the KLT algorithm, reducing the camera movement to mean RMSE residual of 1.27 pixels (calculated at a frame rate of $2 \mathrm{fps}$ ). Subsequently, orthorectified and stabilized grey-scale frames were exported for analysis within the other algorithms. It must be noted that no pre-processing or filtering has been conducted on the frames. This was to ensure the images were consistent for each algorithm. Due to the low flow nature of the study, the exported frames were then sub-sampled into various feature extraction rates including $1,2,4$ and 6 fps.

The image sequences were processed through five different algorithms including KLT, LSPIV, LSPTV, OTV and SSIV, with the varying feature extraction rates and processing configurations (particle identification search area/lengths) as shown in Table 2. The methodology of image-processing for each algorithm is described in Table 1. The surface velocity results for each algorithm are outputs of surface velocity vectors or trajectories. For KLT, LSPIV, LSPTV and SSIV, the outputs were surface velocity vector maps, which were gridded to $0.5 \mathrm{~m}$ cells for comparison purposes (Figure 4 ). The output results for OTV were in the form of trajectories, based on the length of the trajectory chosen. Therefore, the midpoint of each trajectory has been extracted and gridded to $0.5 \mathrm{~m}$ cells, in order to perform accurate comparisons against the four vector-based algorithms (Figure 4).

Table 2. Parameters chosen for the sensitivity analysis for all algorithms, all measurements in pixel sizes. IA = Interrogation Area $(\mathrm{px}), \mathrm{SA}=$ Search Area $(\mathrm{px}), \mathrm{BS}=$ Block Size $(\mathrm{px}), \mathrm{TL}=$ Trajectory Length (px).

\begin{tabular}{cccc}
\hline Algorithm & Configuration 1 & Configuration 2 & Configuration 3 \\
\hline LSPIV & 32 IA, 16 SA & 64IA, 32 SA & 128 IA, 64 SA \\
LSPTV & 32 IA & 64 IA & 128 IA \\
SSIV & 32 IA & $64 \mathrm{IA}$ & 128 IA \\
KLT & $31 \mathrm{BS}$ & $63 \mathrm{BS}$ & $127 \mathrm{BS}$ \\
OTV & $50 \mathrm{TL}$ & $100 \mathrm{TL}$ & 200 TL \\
\hline
\end{tabular}


(a) KLT

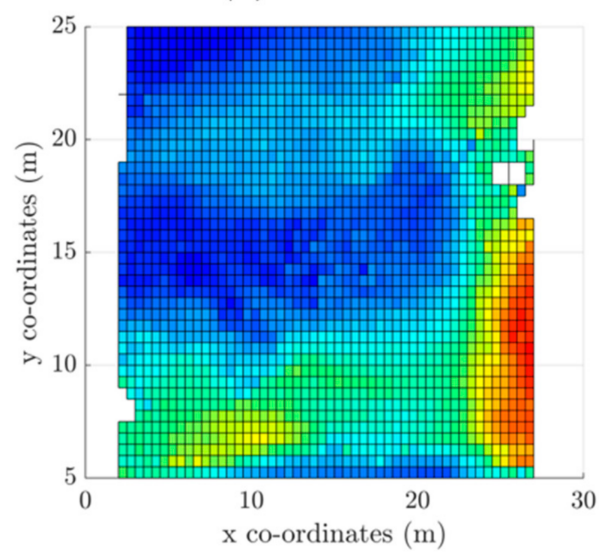

(c) LSPTV

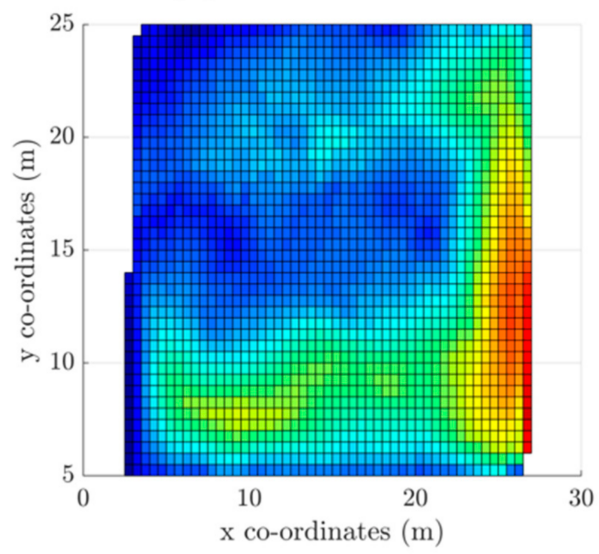

(e) OTV Trajectories

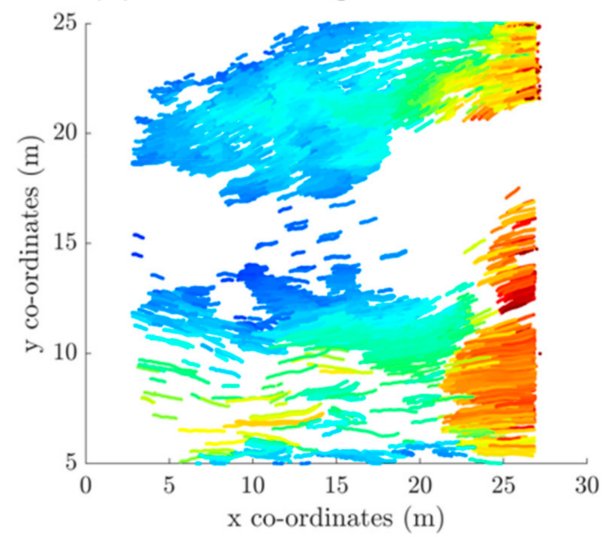

(b) LSPIV

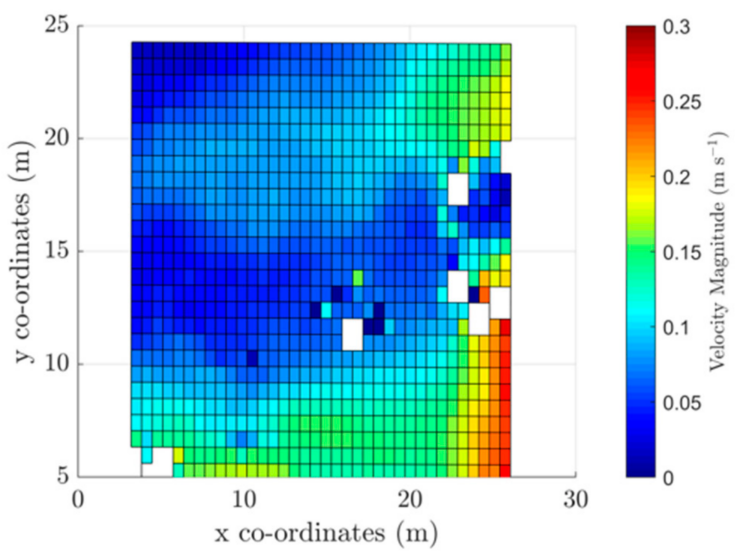

(d) SSIV

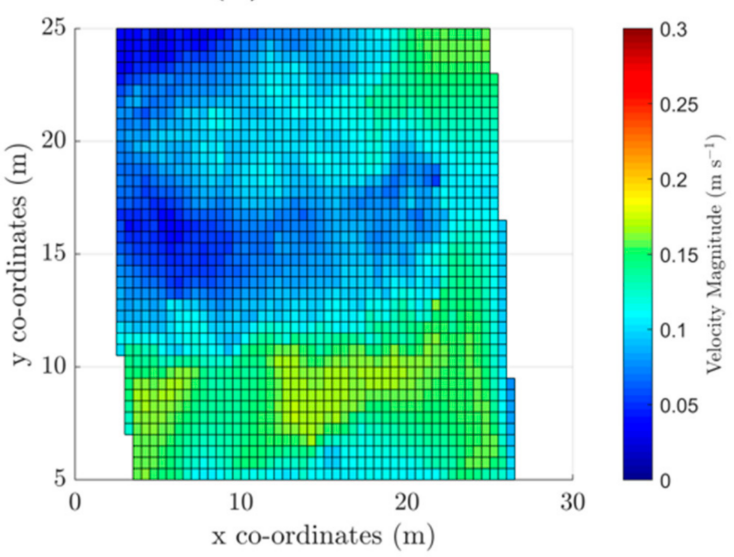

(f) OTV Gridded

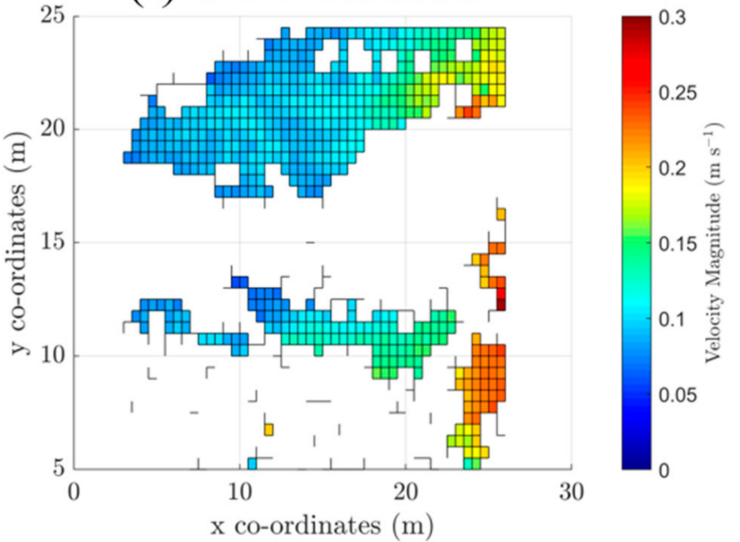

Figure 4. Gridded surface velocity maps for all algorithms, including the original trajectory map for $\operatorname{OTV}(\mathbf{e})$.

\subsection{Data Analysis}

\subsubsection{Sensitivity Analysis}

An analysis to determine the sensitivity of each algorithm to varying parameter configurations was performed on Video A. This sensitivity analysis was performed at two cross-sections, located at $10 \mathrm{~m}$ and $20 \mathrm{~m}$ on the $x$-axis (Figure 2). Two cross-sections which did not correspond to the ADCP reference measurements were chosen, to allow the analysis to be as objective as possible. Sensitivity 
was assessed by varying the particle identification and search area/ trajectory lengths, and feature extraction rates. The three configurations were processed with four different extraction rates: 1, 2, 4 and $6 \mathrm{fps}$, providing a total of 12 configurations for each algorithm (Table 2). First, the velocity outputs for each of the algorithms were gridded at $0.5 \times 0.5 \mathrm{~m}$ cells. The average of the trajectories/vectors within each of these cells were carried forward. This resolution was chosen to split the cross-section into approximately 40 cells. This size was deemed large enough to ensure data was present in almost all cells, but have sufficient sensitivity to the cross-sectional changes in velocities. Following this, a median value for each cell using input data from across the 12 different configurations was computed. A score is attached to each configuration for each cell based on the absolute deviation between the configuration specific velocity, and the median cell velocity. These scores were added up along the cross-section, providing a total score for each configuration; the lower the score, the less variance that is associated among the configurations. The calculation of the lowest recorded score was based on an average of scores from both cross-sections assessed. Furthermore, configurations that contain less than $70 \%$ coverage of data for each cross-section, have been excluded from the analysis due to needing a sufficient quantity of information for an accurate comparison between algorithms.

\subsubsection{Comparisons of Image Velocimetry Data and ADCP Rreference Data}

Following image-processing, all image velocimetry outputs (velocity vectors or trajectories) have been transformed into the same co-ordinate system as the GCP survey data. This enabled cross-sections which correspond to those taken with the ADCP to be extracted, and comparisons between the ADCP-based velocities and image velocimetry estimates to be made.

The configuration which performed the best for each algorithm during the sensitivity analysis has been chosen for comparisons against the ADCP data. The most representative configurations have been applied to Video B for further comparisons, and tests of repeatability. Nash-Sutcliffe (NSE) analysis has also been performed to compare each image velocimetry cross-sectional measurement to the ADCP measurements directly. This assessment will aid the interpretation of which algorithm is calculating surface velocities most similar to the ADCP; an NSE result of 1 represents a perfect correspondence.

\section{Results}

\subsection{ADCP Results}

To obtain surface velocity estimates from ADCP data, characteristic velocity profiles were fitted to the available ADCP velocity data (Figure 5). While the logarithmic and power relationships provide fairly good agreement with ADCP data, they seem to overestimate the surface velocity magnitudes as they are unable to account for air-water sheer effect of the shallow flow. In order to estimate the impact of the air-surface sheer effect, velocity profiles were also analyzed using second- and third-degree polynomials (Figure 5). It was determined that the ratio between surface and depth-averaged velocity is close to unity, and, for that reason, depth-averaged velocity magnitude from the ADCP data was used as an estimate of surface velocity magnitude in all further analyses.

Surface velocities estimated from the ADCP data are consistent with the topography and bathymetry of the river at the site: Section 1 (upstream) is positioned immediately after a left bend and is characterized by larger depths and velocities on the right bank ( $y$-axis $5 \mathrm{~m}$ (Figure 2)), while Section 3 (downstream) is positioned immediately before a right bend where the bathymetry is changing rapidly and the velocity field is bimodal. Average surface velocity magnitudes in the ROI were estimated to be in range between 0.10 to $0.14 \mathrm{~m} \mathrm{~s}^{-1}$, and are generally increasing in the downstream direction due to changes in bathymetry (average depth reduces in the downstream direction) (Figure 6). The minimal and maximal surface velocities were estimated to be 0 and $0.32 \mathrm{~m} \mathrm{~s}^{-1}$, respectively. Velocity magnitudes close to the high-slope river edges show significantly higher velocities than expected. This is likely a result of side-lobe interference. 


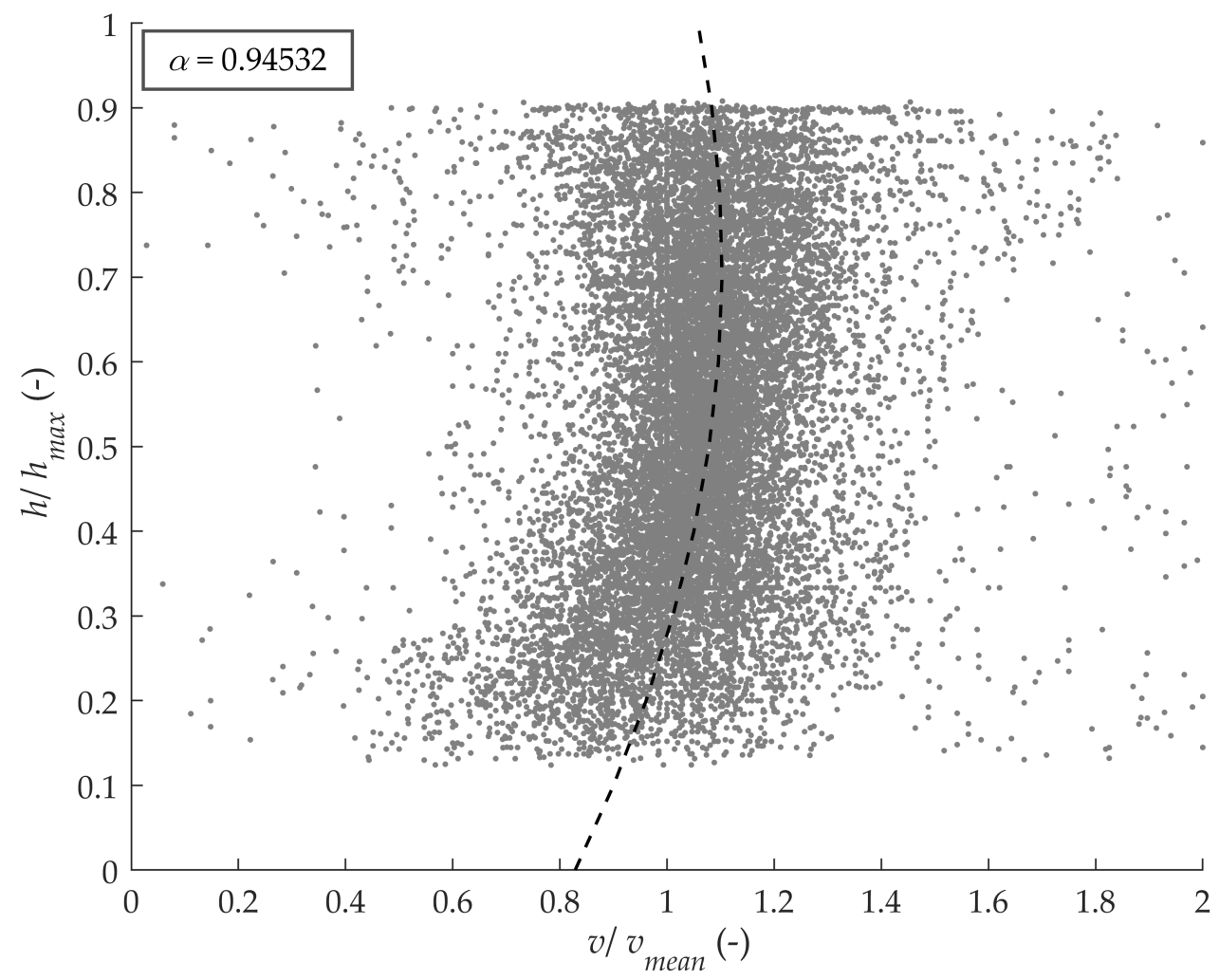

Figure 5. ADCP relative velocity magnitude data. Characteristic velocity profile obtained using second-degree polynomial fit. The alpha value represents the ratio between the extrapolated surface velocity and the depth-averaged velocity.

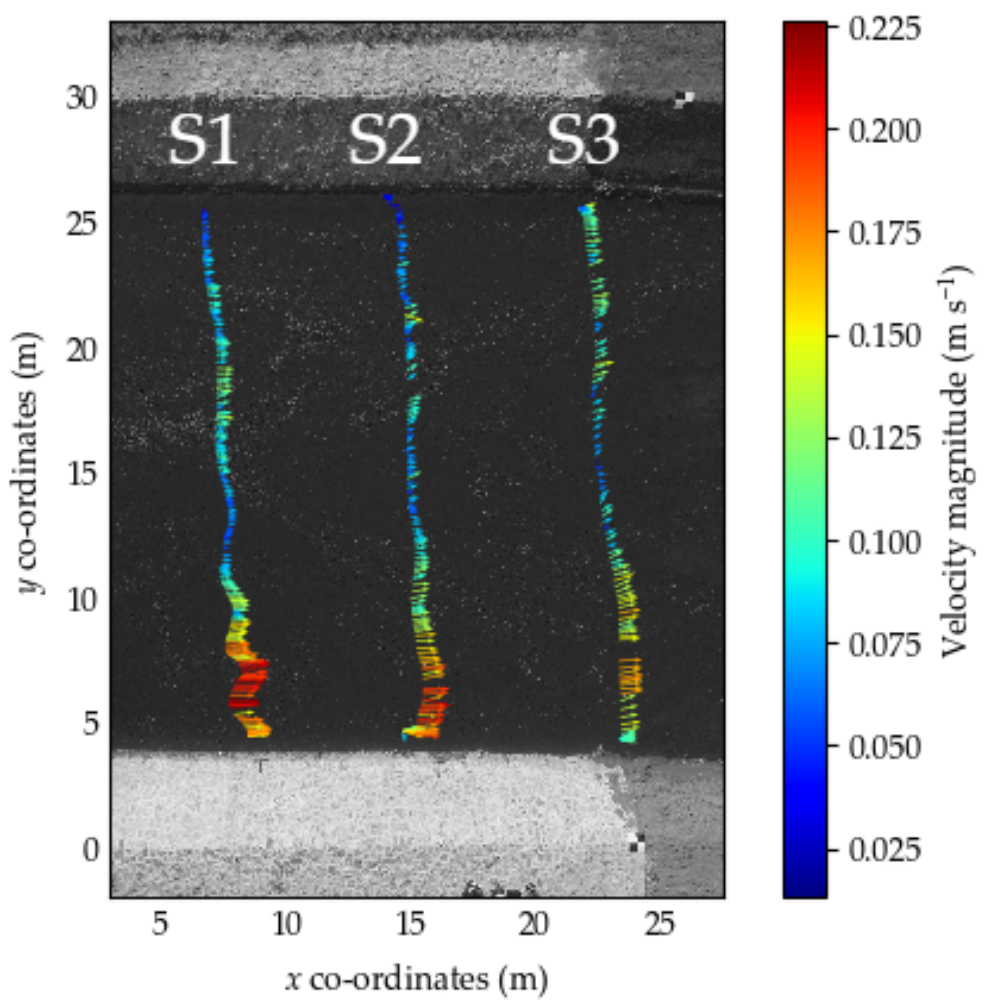

Figure 6. Quiver plot of the ROI, showing velocity magnitudes and directions for Sections 1-3 (left to right). 


\subsection{Sensitivity Analysis}

Results of the sensitivity analysis that was performed according to the procedure described in Section 2.3.1 are visualized in Figure 7. The calculated sensitivity scores are summarized in Table 3. Figure 7a highlights that KLT is relatively insensitive to changing parameters; along the cross-sections there is very little deviation from the median of all configurations. Nevertheless, small variations do occur at the higher flow rates, at both cross-sections. Velocities range between $0.13-0.17 \mathrm{~m} \mathrm{~s}^{-1}$, where the median velocity values are recorded as $0.16 \mathrm{~m} \mathrm{~s}^{-1}$ and $0.12 \mathrm{~m} \mathrm{~s}^{-1}$ at the $10 \mathrm{~m}$ and $20 \mathrm{~m}$ cross-sections, respectively. Thus, configurations deviate from the median by up to $0.02 \mathrm{~m} \mathrm{~s}^{-1}$ for each cross-section (Figure 7a,b). The sensitivity analysis scores are consistently lower for feature extraction rates of $2 \mathrm{fps}$ and $4 \mathrm{fps}$, with average scores of 0.154 and 0.146 , respectively, compared to feature extraction rates of $1 \mathrm{fps}$ and $6 \mathrm{fps}$, which have an average score of 0.282 and 0.43 , respectively. This suggests that the feature extraction rate could influence the surface velocity measurements calculated using KLT during the conditions of focus (Table 2). Further investigations and tests of the algorithm at varying flow rates would allow verification of this assumption. However, from these observations, it is unlikely that varying the particle identification area size has much influence upon the accuracy of surface velocity measurements. The configuration with least variance from the mean for KLT was a feature extraction rate of $2 \mathrm{fps}$, and a block size of 63 pixels, which had sensitivity scores of 0.199 and 0.133 for the $10 \mathrm{~m}$ and $20 \mathrm{~m}$ cross-sections, respectively.

The sensitivity analysis for OTV highlights very little variation between configurations at both cross-sections. At the $20 \mathrm{~m}$ cross-section, it is clear that the configurations processed cannot detect the slower flows (recorded as approximately $0.08 \mathrm{~m} \mathrm{~s}^{-1}$ by all other algorithms median value) within the center of the channel ( $x$-axis 13-20 m) (Figure 7d). Nevertheless, the surface velocity profiles reconstructed are comparable to those of the other algorithms assessed. The particle identification search length of 200 pixels $(2 \mathrm{~m})$ proved to be too large for the accurate detection of slower particles in the center of the stream to successfully estimate the surface velocity. Since less than $70 \%$ of data were available in each cross-section, this configuration had to be removed from the analysis. This result highlights that OTV can be sensitive to the particle trajectory length threshold and needs to be considered when addressing different flow rates (especially when the ROI exhibits varying flow regimes). The sensitivity scores recorded for the remaining configurations of OTV, are the lowest across all algorithms, thus demonstrating that they do not vary from the median of all configurations significantly. The feature extraction rate of $4 \mathrm{fps}$ provides the lowest scores overall, irrespective of the trajectory lengths, recording sensitivity scores of all less than 0.05 . Furthermore, on average, a trajectory length of 100 pixels $(1 \mathrm{~m})$ provides the lowest sensitivity scores overall, although scores do not differ significantly from the 50-pixel trajectory configurations (Table 3). Considering the significant difference between the 50 pixel and 100-pixel trajectory length, when compared to the 200 pixel trajectory, it is clear that OTV is sensitive to changing the particle trajectory length, with respect to the flow rate. The configuration with least variance from the mean for OTV was a feature extraction rate of $4 \mathrm{fps}$, and a trajectory length of 50 pixels $(0.5 \mathrm{~m})$, which had sensitivity scores of 0.042 and 0.03 for the $10 \mathrm{~m}$ and $20 \mathrm{~m}$ cross-sections, respectively.

Figure $7 \mathrm{e}, \mathrm{f}$ highlight that the LSPIV sensitivity analysis provides very similar cross-sectional profiles to that of the KLT results, albeit with slightly more variation. The highest degrees of variation are in the $20 \mathrm{~m}$ cross-section, at $17 \mathrm{~m}$ on the $x$-axis, where the configurations vary by up to $0.07 \mathrm{~m} \mathrm{~s}^{-1}$ from the median of all configurations; some variations also occur between $15-20 \mathrm{~m}$ on the $x$-axis (Figure 7f). The $10 \mathrm{~m}$ cross-section also encounters some variations, between 5-12 $\mathrm{m}$ on the $x$-axis, where surface velocities vary by $0.06 \mathrm{~m} \mathrm{~s}^{-1}$ (Figure $7 \mathrm{e}$ ). At the $10 \mathrm{~m}$ cross-section, the highest deviations from the median of all configurations occur in the faster velocities, towards the origin of the $x$-axis $(5 \mathrm{~m})$, with deviations of up to $0.04 \mathrm{~m} \mathrm{~s}^{-1}$. The lowest sensitivity scores recorded for LSPIV are 0.093 and 0.054 for the $10 \mathrm{~m}$ and $20 \mathrm{~m}$ cross-sections, respectively, which are recorded for a feature extraction rate of $4 \mathrm{fps}$ and configuration 3 (128 pixel particle identification area) (Table 3). Sensitivity scores show that LSPIV is very sensitive to parametrization in terms of both feature extraction rate and IA size. 
On average, scores are generally lower for extraction rates of $2 \mathrm{fps}$ and $6 \mathrm{fps}$, where configurations 1 and 3 at 6 fps record scores of 0.072 and 0.062, respectively (Table 3).
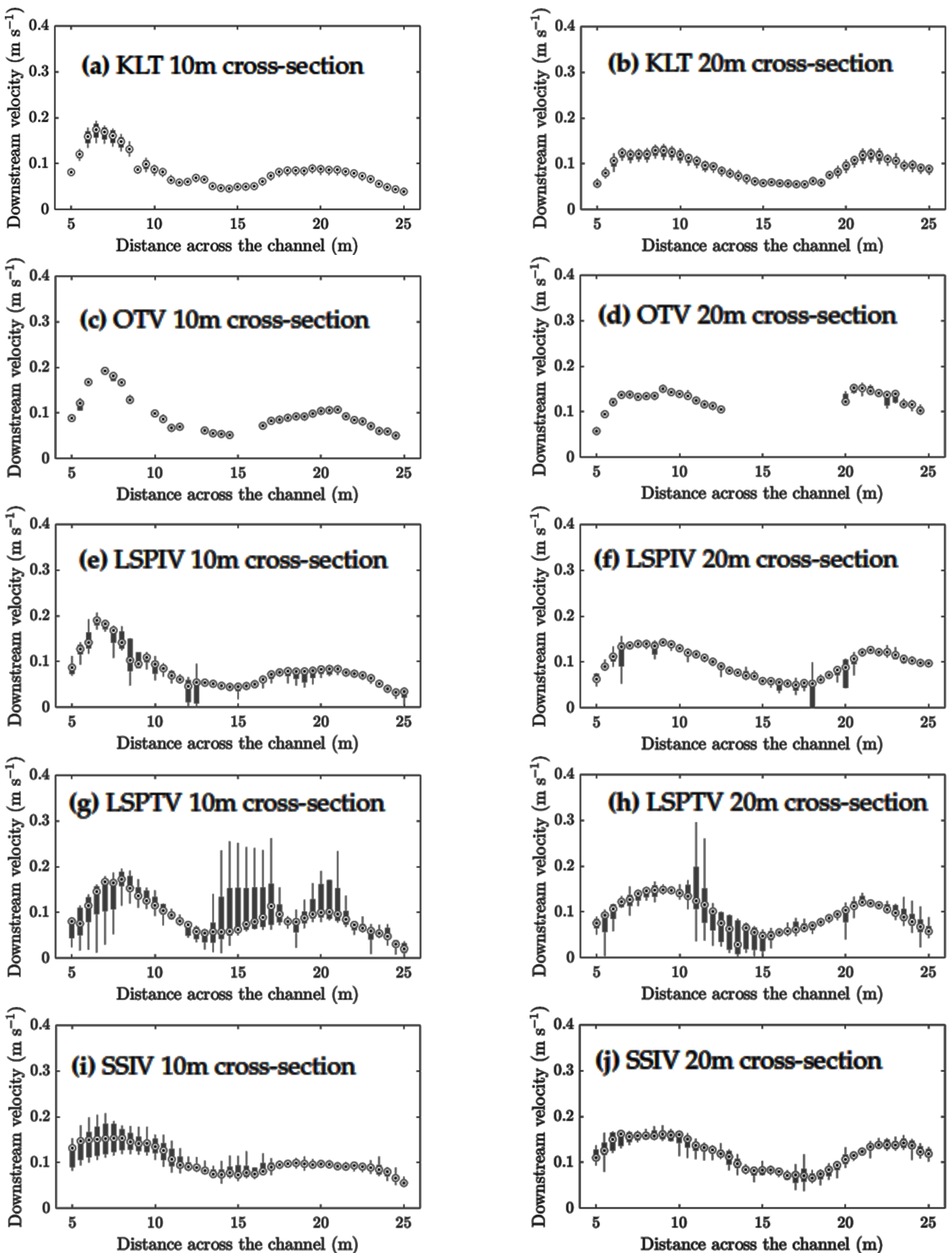

Figure 7. Sensitivity Analysis results for all algorithms at two cross-sections (Represented by red dashed lines in Figure 2). The distance across the channel relates to the y co-ordinates in Figures 2, 4 and 6. $5 \mathrm{~m}$ is the right bank, and $25 \mathrm{~m}$ is the left bank. 
Table 3. Sensitivity scores for all algorithms at cross-sections $10 \mathrm{~m}$ and $20 \mathrm{~m}$. (C1 = Configuration 1 , C2 = Configuration 2, and C3 = Configuration 3-See Table 1). Light colors represent lowest sensitivity scores, increasing as the colors darken. Darkest values are those which have been excluded from the sensitivity analysis. The configurations which have the lowest sensitivity scores are reported in bold text for each algorithm.

\begin{tabular}{|c|c|c|c|c|c|c|c|c|c|c|c|c|c|}
\hline & & & $1 \mathrm{fps}$ & & & $2 \mathrm{fps}$ & & & $4 \mathrm{fps}$ & & & $6 \mathrm{fps}$ & \\
\hline \multirow{3}{*}{ KLT } & & $\mathrm{C} 1$ & $\mathrm{C} 2$ & C3 & $\mathrm{C} 1$ & $\mathrm{C} 2$ & C3 & $\mathrm{C} 1$ & $\mathrm{C} 2$ & $\mathrm{C} 3$ & $\mathrm{C} 1$ & $\mathrm{C} 2$ & C3 \\
\hline & $10 \mathrm{~m}$ & 0.250 & 0.227 & 0.243 & 0.140 & 0.119 & 0.147 & 0.117 & 0.123 & 0.138 & 0.389 & 0.392 & 0.384 \\
\hline & $20 \mathrm{~m}$ & 0.215 & 0.259 & 0.339 & 0.186 & 0.133 & 0.198 & 0.159 & 0.177 & 0.164 & 0.480 & 0.507 & 0.481 \\
\hline \multirow{2}{*}{ OTV } & $10 \mathrm{~m}$ & 0.044 & 0.053 & N/A & 0.012 & 0.011 & N/A & 0.042 & 0.03 & $\mathrm{~N} / \mathrm{A}$ & 0.074 & $\mathrm{~N} / \mathrm{A}$ & $\mathrm{N} / \mathrm{A}$ \\
\hline & $20 \mathrm{~m}$ & 0.098 & 0.086 & N/A & 0.106 & 0.101 & N/A & 0.03 & 0.05 & N/A & 0.09 & 0.07 & N/A \\
\hline \multirow{2}{*}{ LSPIV } & $10 \mathrm{~m}$ & 0.338 & 0.129 & 0.190 & 0.105 & 0.069 & 0.163 & 0.256 & 0.311 & 0.093 & 0.143 & 0.106 & 0.126 \\
\hline & $20 \mathrm{~m}$ & 0.237 & 0.229 & 0.094 & 0.227 & 0.191 & 0.165 & 0.185 & 0.167 & 0.054 & 0.072 & 0.212 & 0.062 \\
\hline \multirow{2}{*}{ LSPTV } & $10 \mathrm{~m}$ & 0.407 & 0.588 & 1.075 & 0.352 & 0.498 & 1.989 & 0.366 & 0.580 & 3.007 & 0.395 & 0.895 & 5.325 \\
\hline & $20 \mathrm{~m}$ & 0.313 & 0.309 & 1.239 & 0.241 & 0.552 & 1.120 & 0.198 & 0.566 & 2.533 & 0.202 & 0.625 & 1.902 \\
\hline \multirow{2}{*}{ SSIV } & $10 \mathrm{~m}$ & 0.315 & 0.267 & 0.247 & 0.144 & 0.082 & 0.210 & 0.206 & 0.107 & 0.131 & 0.313 & 0.380 & 0.483 \\
\hline & $20 \mathrm{~m}$ & 0.654 & 0.146 & 0.152 & 0.191 & 0.174 & 0.149 & 0.178 & 0.131 & 0.115 & 0.275 & 0.222 & 0.174 \\
\hline
\end{tabular}

Figure 7 shows that LSPTV is the most sensitive to parametrization relative to all other algorithms. However, the cross-sectional profiles, represented by the median of all configurations, are very similar to those reconstructed by the other algorithms assessed (Figure 7). On average, the $20 \mathrm{~m}$ cross-section results encounter less variation throughout the entire cross-section than the $10 \mathrm{~m}$ cross-section, which encounters the highest degree of variation of all of the algorithms (Figure $7 \mathrm{~g}, \mathrm{~h}$ ). Nevertheless, for LSPTV there is a general trend that across all extraction rates, configuration 1 (32 pixel particle identification area) provides the lowest sensitivity scores (Table 3), and therefore the least variance within surface velocity measurements in relation to the median of all configurations and extraction rates. For configuration 1 and cross-section $20 \mathrm{~m}$ the sensitivity scores are the lowest recorded for LSPTV, with scores of $0.241,0.198$ and 0.202 , for feature extraction rates of $2 \mathrm{fps}, 4 \mathrm{fps}$ and $6 \mathrm{fps}$, respectively. The configuration with least variance from the median for LSPTV was a feature extraction rate of $4 \mathrm{fps}$ and a particle identification area of 32 pixels (Table 3). The configuration with most variance from the median for LSPTV was $6 \mathrm{fps}$, with an particle identification area of 128 pixels (Table 3).

Similar to KLT, SSIV seems to encounter higher variations of surface velocity measurements at the higher flow rates. At the $10 \mathrm{~m}$ cross-section, between $5-10 \mathrm{~m}$ on the $x$-axis, variations occur between 0.1 and $0.19 \mathrm{~m} \mathrm{~s}^{-1}$, where the mean of all configurations is $0.14-0.15 \mathrm{~m} \mathrm{~s}^{-1}$ (Figure 7i). On average, the $20 \mathrm{~m}$ cross-section encounters less variation from the median for all configurations, and very little sensitivity is present (Figure 7j). Moreover, the sensitivity scores for the $20 \mathrm{~m}$ cross-section are on average lower than those calculated for the $10 \mathrm{~m}$ cross-section (Table 3). Overall, the lowest sensitivity scores are recorded with feature extraction rates of $2 \mathrm{fps}$ and $4 \mathrm{fps}$, which are predominantly less than 0.2 (Table 3). The configuration with least variance from the median for SSIV was a feature extraction rate of $2 \mathrm{fps}$, with an particle identification area of 64 pixels.

In summary, at the $10 \mathrm{~m}$ cross-section, algorithms are the most sensitive to changing parameters within the faster reaches of the transect $(x$-axis 5-10 m) (Figure 7). Specifically, the results obtained from all configurations for KLT, LSPIV and SSIV vary from the mean with differences of up to $0.07 \mathrm{~m} \mathrm{~s}^{-1}$ within the faster flows (Figure 7a,e,i). However, within the center of the channel and toward the left bank ( $x$-axis 25), variations of the measurements for KLT, LSPIV and SSIV are minimal. LSPTV, on the other hand, experienced the highest variations within the center of the channel where flows are lower (approx $0.06 \mathrm{~m} \mathrm{~s}^{-1}$ ). OTV experienced very little sensitivity at the $10 \mathrm{~m}$ cross-section, whereas at the $20 \mathrm{~m}$ cross-section few trajectories could be retained in the center of the channel, where flows were slower. For all algorithms, the results of the sensitivity analysis at the $20 \mathrm{~m}$ cross-section provided slightly more varied results when compared to those calculated at the $10 \mathrm{~m}$ cross-section. The $10 \mathrm{~m}$ cross-section results provide the most sensitivity towards the origin of the $x$-axis $(5 \mathrm{~m})$; however at the $20 \mathrm{~m}$ cross-section the highest sensitivity is occurring in the center of the channel and towards the 
$x$-axis of $25 \mathrm{~m}$ (Figure 7). Nevertheless, KLT and OTV highlight the least amount of variance from the median of all configurations. LSPIV and SSIV experienced the most variations within the higher flow rates of each cross-section, and LSPTV proves to be the most sensitive to parametrization. Based on the results of the sensitivity analysis, configurations selected for the comparison against the ADCP reference data for videos $\mathrm{A}$ and $\mathrm{B}$ are:

- $\quad$ KLT-2 fps and Block size of 63 pixels

- OTV—4 fps and Trajectory length of $0.5 \mathrm{~m}$ (50 pixels)

- $\quad$ LSPIV-4 fps and Interrogation Area of 128 pixels

- $\quad$ LSPTV - 4 fps and Interrogation Area of 32 pixels

- SSIV-2 fps and Interrogation Area of 64 pixels

\subsection{Comparisons against $A D C P$ Measurements}

Two videos (Video A and Video B) have been used for the comparison of image velocimetry algorithms against ADCP reference data. The configurations which provided the lowest sensitivity scores in the sensitivity analysis have been used for the comparisons against the ADCP reference cross-sections. Three cross-sections within the region of interest have been used for the comparison against ADCP data, referred to as S1, S2 and S3 (as detailed in Figure 2), from upstream to downstream, respectively (Figures 8 and 9).

At cross-section $\mathrm{S} 1$ for Video A, Figure $8 \mathrm{~b}$ highlights that most image velocimetry algorithms follow the same trend in terms of locations and magnitude of differences from the ADCP. Nevertheless, at $\mathrm{S} 1$ all image velocimetry algorithms predominantly underestimated the ADCP by up to $0.05 \mathrm{~m} \mathrm{~s}^{-1}$ throughout much of the cross-section. KLT and LSPIV predominantly underestimated the ADCP, by up to $0.05 \mathrm{~m} \mathrm{~s}^{-1}$ in the center of the cross-section, and toward the origin of the $x$-axis by up to $0.1 \mathrm{~m} \mathrm{~s}^{-1}$ (Figure $8 \mathrm{~b}$ ). They are, however, in the best agreement with the ADCP at S1 compared to other algorithms, with NSE values of 0.535 and 0.4905 , respectively. These are the best recorded NSE scores for KLT and LSPIV, overall. OTV records an NSE value of 0.3592, which is the best recorded NSE score for OTV. In areas whereby data is available, the OTV results reconstruct a similar profile to the ADCP, only differing by up to $0.03 \mathrm{~m} \mathrm{~s}^{-1}$ throughout most of the cross section.

At S2 for Video A, all algorithms reconstruct a very similar cross-sectional profile to the ADCP; however SSIV and LSPTV overestimated the ADCP throughout the majority of the cross-section by approximately $0.05 \mathrm{~m} \mathrm{~s}^{-1}$. Toward the origin of the $x$-axis $(5 \mathrm{~m})$, for both $\mathrm{S} 1$ and S2 cross-sections, all algorithms underestimate the ADCP by up to $0.12 \mathrm{~m} \mathrm{~s}^{-1}$ and $0.2 \mathrm{~m} \mathrm{~s}^{-1}$, respectively (Figure $8 \mathrm{~d}$ ). The image velocimetry measurements collected at $\mathrm{S} 2$ for Video B, provide measurements that are, on average, in the best agreement with the ADCP (Figure 9c). For both videos, from $11 \mathrm{~m}$ to $25 \mathrm{~m}$ $(x$-axis), all image velocimetry algorithms reconstruct a very similar cross-sectional profiles to that recorded from the ADCP (Figures $8 \mathrm{c}$ and $9 \mathrm{c}$ ). Surface velocity measurements differ from the ADCP measurements by up to $0.02 \mathrm{~m} \mathrm{~s}^{-1}$ across the majority of the cross-section, for all algorithms (from $11 \mathrm{~m}$ to $20 \mathrm{~m}$ on the $y$ axis). LSPIV provides the highest NSE value of 0.3005 and 0.4620 , for videos $A$ and $B$ at S2, respectively, which suggests that LSPIV provides measurements that are in the best agreement with the ADCP (Table 4). SSIV also provided a similar NSE value of 0.4104 , for Video B, S2 (Table 4), while KLT, LSPTV and OTV provided lower NSE values of $0.3346,0.2246$ and -0.5141 respectively (Table 4). It is likely these NSE scores are lower, because both algorithms significantly underestimate the ADCP at the origin of the $x$-axis $(5 \mathrm{~m})$, by up to $0.12 \mathrm{~m} \mathrm{~s}^{-1}$ (Figure 9c).

The measurements recorded at $\mathrm{S} 3$ deviate significantly from the reference measurements; all image velocimetry algorithms predominantly overestimate the ADCP measurements throughout the entirety of the cross-section for both videos (Figures $8 \mathrm{f}$ and $9 \mathrm{f}$ ). Throughout $\mathrm{S3}$, the ADCP reference surface velocities range between $0.04-0.19 \mathrm{~m} \mathrm{~s}^{-1}$. KLT and LSPIV provide results which are in the best agreement with the ADCP with velocities ranging between $0-0.07 \mathrm{~m} \mathrm{~s}^{-1}$ on average. However, KLT and LSPIV overestimated the ADCP by greater than $0.1 \mathrm{~m} \mathrm{~s}^{-1}$ toward the origin of the $x$-axis 
(KLT) and in the center of the cross-section (LSPIV) (Figure 8f). LSPTV and SSIV deviate from the reference measurements by up to $0.09 \mathrm{~m} \mathrm{~s}^{-1}$ on average, with surface velocity values ranging between $0.07-0.1 \mathrm{~m} \mathrm{~s}^{-1}$ (Figure 8e). Results for S3 for Video B are of similar nature to those calculated for Video A; image velocimetry measurements deviate significantly from the reference measurements (Figure 9e). LSPIV, LSPTV and OTV deviate the most from the ADCP, with all measurements approximately $0.1 \mathrm{~m}$ s different from the ADCP (Figure 9f). The NSE values for LSPIV, LSPTV and OTV for Video B, S3 are $-1.535,-1.8127$ and -2.3446 , respectively, which are the lowest recorded NSE values for these algorithms throughout the entire dataset of Video B (Table 5). The differences along the cross-section between the ADCP and KLT are less pronounced, with the differences ranging between $0-0.06 \mathrm{~m} \mathrm{~s}^{-1}$ in total; this also gives an NSE score of 0.0593, which is the highest NSE score for S3 (Table 5). Similarly, the SSIV varies from the ADCP range between $0-0.08 \mathrm{~m} \mathrm{~s}^{-1}$, resulting in an NSE value of -0.714 (Figure 9e and Table 5).

On average, KLT, OTV, SSIV and LSPIV are in much better agreement with the ADCP than LSPTV. All NSE values recorded are on average lower for LSPTV when compared to the other algorithms (Tables 4 and 5). Results for all algorithms are relatively consistent between the two videos. However, small variations do occur between the videos for each algorithm. For example, SSIV calculated the surface velocities much more accurately in Video B, when compared to Video A. The reconstructed image velocimetry cross-sectional profiles are slightly more varied from Video B, when compared to Video A. Specifically, for S1, all recorded NSE values are higher for Video A when compared to Video $B$, thus suggesting measurements obtained from Video A are in better agreement with the ADCP than those obtained from Video B. All cross-sectional profiles provide a similar trend to the reference measurements; however, a higher degree of deviation is apparent in Video B.

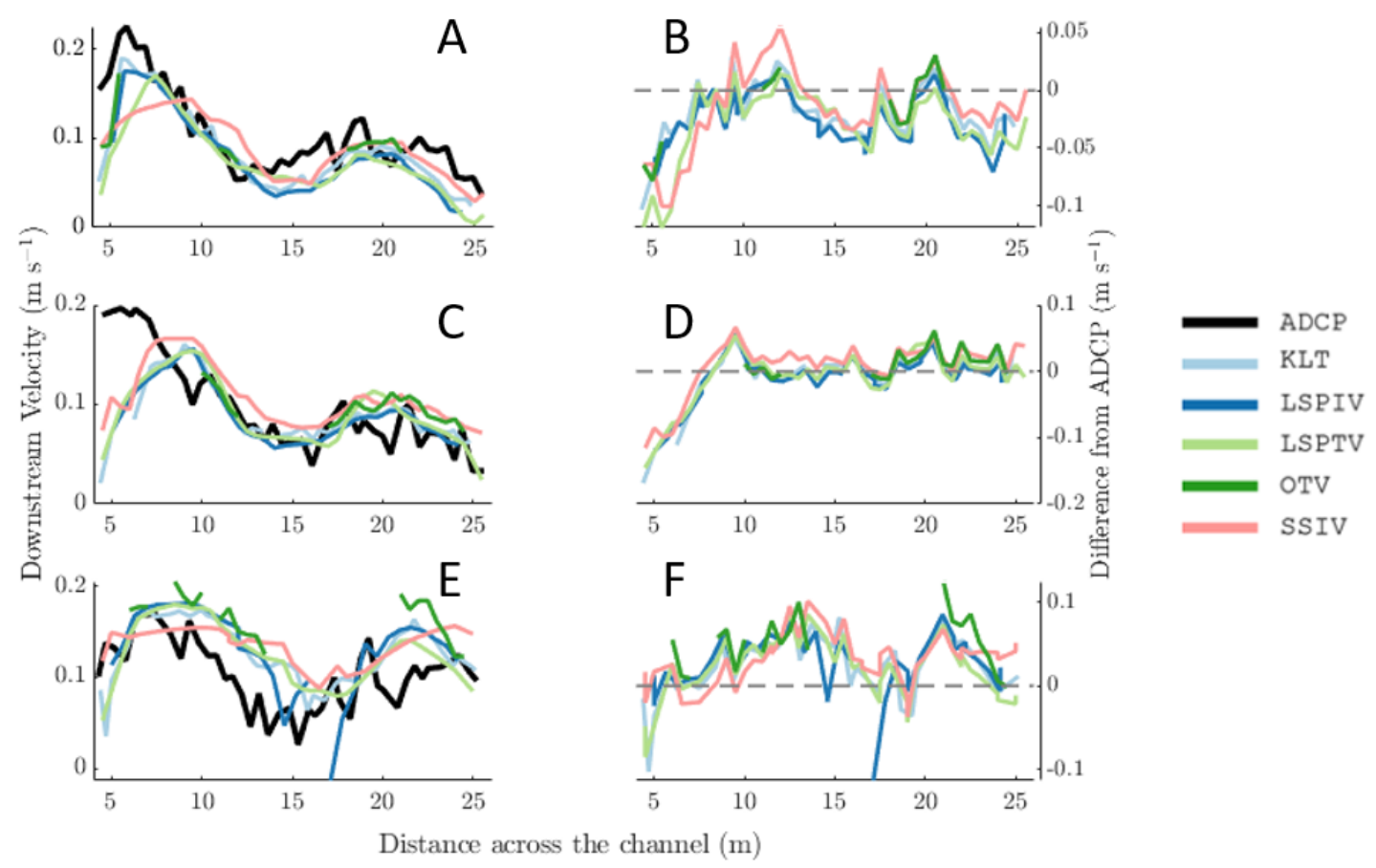

Figure 8. Cross-sectional analysis of Video A processed with all algorithms against the ADCP data. The left panels represent three different cross-sections $(\mathbf{A}=\mathrm{S} 1, \mathbf{C}=\mathrm{S} 2$, and $\mathbf{E}=\mathrm{S} 3)$, the right panels represent the difference from the ADCP of the three cross-sections $(\mathbf{B}=\mathrm{S} 1, \mathbf{D}=\mathrm{S} 2$, and $\mathbf{F}=\mathrm{S} 3)$. The distance across the channel relates to the y co-ordinates in Figures 2, 4 and $6.5 \mathrm{~m}$ is the right bank, and $25 \mathrm{~m}$ is the left bank. 

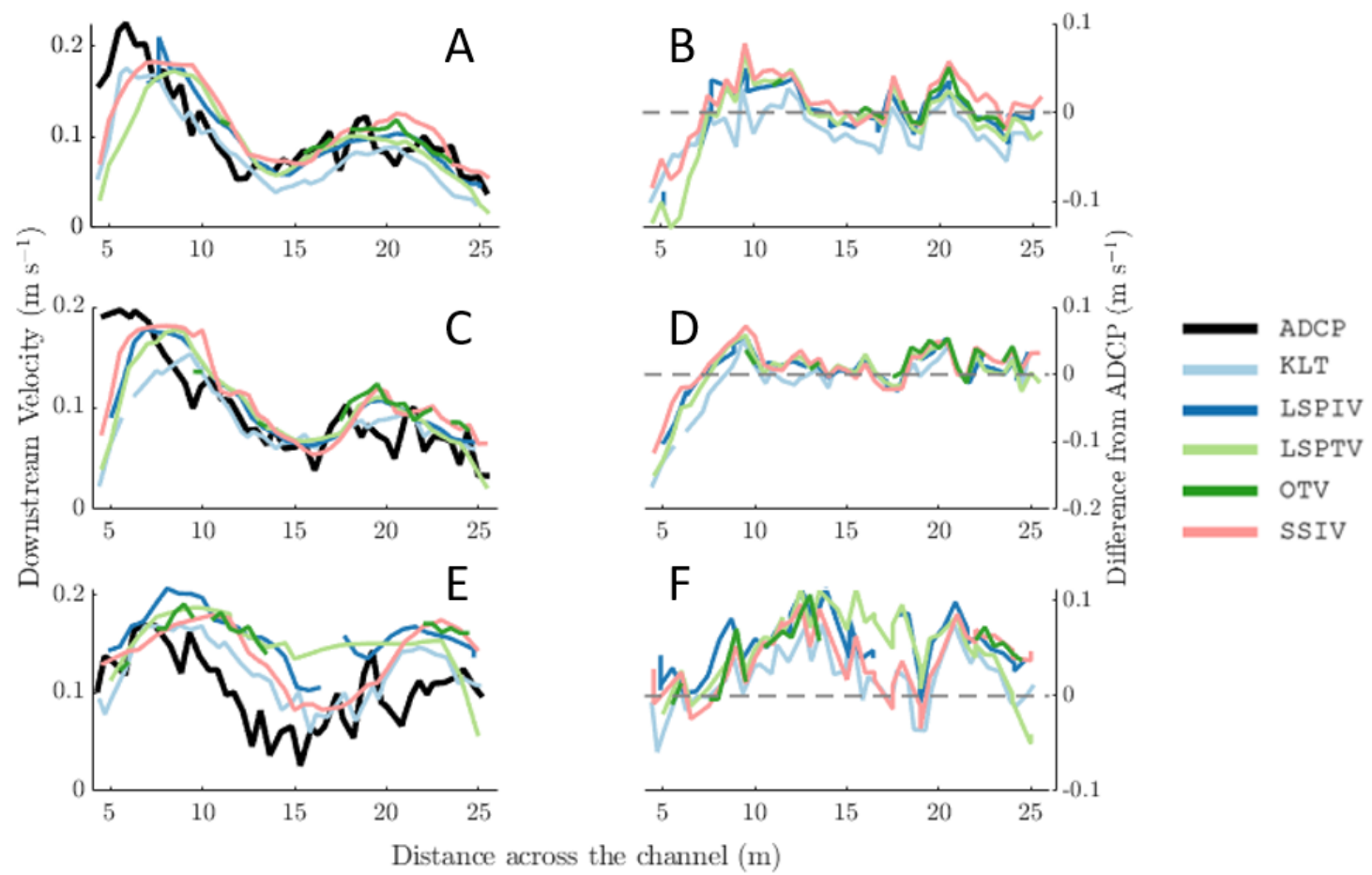

Figure 9. Cross-sectional analysis of Video B processed with all algorithms against the ADCP data. The left panels represent three different cross-sections $((A=S 1, C=S 2$, and $\mathbf{E}=S 3)$, the right panels represent the difference from the ADCP of the three cross-sections $(\mathbf{B}=\mathrm{S} 1, \mathbf{D}=\mathrm{S} 2$, and $\mathbf{F}=\mathrm{S} 3$ ). The distance across the channel relates to the y co-ordinates in Figures 2, 4 and $6.5 \mathrm{~m}$ is the right bank, and $25 \mathrm{~m}$ is the left bank.

Table 4. Nash-Sutcliffe results for Video A. Bold text represents the best recorded value for each algorithm.

\begin{tabular}{cccc}
\hline Algorithm & Cross-Section S1 & Cross-Section S2 & Cross-Section S3 \\
\hline KLT & $\mathbf{0 . 5 3 5}$ & 0.1931 & -0.3091 \\
OTV & $\mathbf{0 . 3 5 9 2}$ & 0.2187 & -2.4196 \\
LSPIV & $\mathbf{0 . 4 9 0 5}$ & 0.3005 & -0.4212 \\
LSPTV & $\mathbf{0 . 1 6 0 9}$ & 0.1763 & -0.2517 \\
SSIV & $\mathbf{0 . 3 8 7 5}$ & 0.236 & -0.3805 \\
\hline
\end{tabular}

Table 5. Nash-Sutcliffe results for Video B. Bold text represents the best recorded value for each algorithm.

\begin{tabular}{cccc}
\hline Algorithm & Cross-Section S1 & Cross-Section S2 & Cross-Section S3 \\
\hline KLT & $\mathbf{0 . 4 8 7 9}$ & 0.3346 & 0.0593 \\
OTV & $\mathbf{- 0 . 3 1 8 9}$ & -0.5141 & -2.3445 \\
LSPIV & 0.3373 & $\mathbf{0 . 4 2 6 0}$ & -1.535 \\
LSPTV & 0.1313 & $\mathbf{0 . 2 2 4 6}$ & -1.8127 \\
SSIV & $\mathbf{0 . 4 6 8 7}$ & 0.4104 & -0.7141 \\
\hline
\end{tabular}

\section{Discussion}

The sensitivity analysis has highlighted that some algorithms are more sensitive than others when changing the feature extraction rate and the particle identification and search area/lengths. Specifically, KLT, LSPIV and SSIV show a higher degree of sensitivity within faster flowing reaches of the cross-sections, while LSPTV highlights more variation within the results throughout slower flowing reaches (Figure 7). In particular, the sensitivity analysis has highlighted that KLT and SSIV are 
more sensitive to changing the feature extraction rate, rather than the particle identification and search areas. For example, KLT and SSIV provided lower sensitivity scores with feature extraction rates of $2 \mathrm{fps}$ and $4 \mathrm{fps}$, on average (Table 3). Whereas LSPIV proves to be sensitive across all configurations and feature extraction rates, the variability between the two parameters is very similar.

On the other hand, OTV proves to be more sensitive to changing the trajectory length. Throughout all feature extraction rates, particles were not successfully tracked for $2 \mathrm{~m}$ or more, therefore, trajectories were rejected, and little data was generated. This highlights that depending on the flow rate, suitable trajectory length must be chosen to sample a large enough quantity of data for surface velocity analysis. The fact that trajectory lengths of $0.5 \mathrm{~m}$ and $1 \mathrm{~m}$ provided very low sensitivity scores across all feature extraction rates implies that if the trajectory length is correctly selected, the feature extraction rate has little influence on calculated velocity values. These results are corroborated by a previous study conducted by Tauro et al. [19], the optimum trajectory length was defined as $1 \mathrm{~m}$ in flows of approx. $0.4 \mathrm{~m} \mathrm{~s}^{-1}$, while changing the feature extraction rate did not significantly affect the OTV surface flow velocities calculated. Throughout this analysis, in order to form detailed comparisons between the different algorithms assessed, the midpoint of each trajectory was chosen for all OTV results. This method of data extraction has resulted in some cross-sections with little or no data available, therefore, future analysis should consider using all data available for a comprehensive analysis. As little research has been conducted upon the newly developed KLT-IV and OTV algorithms it would be interesting to conduct a larger scale sensitivity analysis during a range of flow rates and varying morphological conditions. Further analysis would allow a robust understanding of the applications and limitations of both algorithms [19,20].

Similar to OTV, LSPTV highlighted less sensitivity to changing the feature extraction rate than to altering the interrogation area size. Since decreasing IA size under the study conditions (low flows) is associated with better sensitivity scores, it is possible that further testing of LSPTV, with interrogation areas of less than 32 pixels could provide more accurate surface velocity reconstructions [16]. Furthermore, LSPTV typically undergoes a post-processing vector validation to remove spurious results [16]. However, because post-processing was not explicitly conducted on the other algorithms, it was decided that this phase would not be conducted for LSPTV. Thus, the RAW velocity vectors were used for the sensitivity analysis and comparisons. Because of the strong dependence of LSPTV on the particle appearance, spurious results are more common than when using the other algorithms. Consequently, LSPTV proved the least representative measurements when compared to the ADCP and predominantly overestimated the reference measurements (Figures 8 and 9). During the processing of all the configurations and algorithms, no pre-processing or filtering procedures were applied on the imagery. Therefore, this could have had impact upon the sensitivity of the different algorithms. Typically, when processing river flow data with LSPIV, LSPTV or SSIV, images are pre-processed to enhance the appearance of the particles within the channel $[18,25]$. However, because KLT and OTV do not naturally use pre-processing techniques, it was decided that these would not be computed to allow for a raw comparison of all techniques. It is known that some algorithms would benefit from image pre-processing and thus the results of their application could be further improved. However, the understanding of comparative performance of algorithms with the use of raw images is of great value for inexperienced users. Finding an optimal combination of pre-processing filters and their best settings, and deciding on the correct order of filter application is a challenging task. Moreover, the best pre-processing settings may vary for different algorithms (e.g., PTV may be more sensitive to preserving the shape of particles, and thus noise removal suitable for PIV may be too much for PTV). Since justification of the choice of pre-processing techniques could not be done within the scope of the current paper, it was decided not to introduce additional unexplained variables in order to provide maximum value not only for the scientific community, but also for those who are only starting to explore different methods of image velocimetry. As presented in Figures 8 and 9, the image velocimetry configurations that have been chosen based on the sensitivity analysis results compare well with the ADCP measurements for cross-sections S1 and S2. However, larger deviations occur at S3, for all 
algorithms. This may be due to the irregular bathymetry that in turn, leads to variable flow regimes in the ROI. For all cross-sections, the Nash-Sutcliffe values suggest that the KLT measurements are in the best agreement with the ADCP, on average (Tables 4 and 5). Table 6 provides a summary of the advantages and limitations of each algorithm assessed throughout this research.

Table 6. Advantages and limitations of the five image velocimetry methods applied throughout this research.

\begin{tabular}{|c|c|c|}
\hline Algorithm & Advantages & Limitations/Requirements \\
\hline KLT & $\begin{array}{l}\text { - Changing particle identification area does not } \\
\text { significantly affect the surface velocity results } \\
\text { - } \quad \text { Simple to learn and calculate velocities } \\
\text { - } \quad \text { Provides sub-pixel resolution of surface } \\
\text { velocity vectors/trajectories }\end{array}$ & $\begin{array}{l}\text { - Small variations occur in results when feature } \\
\text { extraction rate is altered } \\
\text { - Specific camera model is required in the } \\
\text { application before calculations can be } \\
\text { performed } \\
\text { - The performance of KLT has not been widely } \\
\text { tested under a variety of } \\
\text { hydrological conditions. }\end{array}$ \\
\hline OTV & $\begin{array}{l}\text { - Relatively insensitive to changing the feature } \\
\text { extraction rate } \\
\text { - Relatively insensitive to seeding density } \\
\text { and shape } \\
\text { - } \quad \text { Reconstructs seeding trajectories }\end{array}$ & $\begin{array}{l}\text { - Relatively sensitive to changing the } \\
\text { trajectory length } \\
\text { - Requires basic information on flow direction } \\
\text { and geometry } \\
\text { - Requires a Linux environment } \\
\text { - Specific camera model is required in the } \\
\text { application before calculations can be } \\
\text { performed }\end{array}$ \\
\hline LSPIV & $\begin{array}{l}\text { - } \quad \text { Provides full flow field of information } \\
\text { - } \quad \text { vest widely used and documented image } \\
\text { - Shape and size of particles do not need to be } \\
\text { defined, thus can potentially be applied to } \\
\text { naturally occurring surface features. }\end{array}$ & $\begin{array}{l}\text { - Relatively sensitive to changing both the } \\
\text { feature extraction rate and the particle } \\
\text { identification area } \\
\text { - } \quad \text { Requires continuously and densely seeded } \\
\text { surfaces [35]. } \\
\text { - } \quad \text { Training is required for accurate surface } \\
\text { velocity estimations } \\
\text { - Velocity vectors are arbitrarily assigned at the } \\
\text { center of the interrogation window } \\
\text { - Specific camera model is required in the } \\
\text { application before calculations can be } \\
\text { performed }\end{array}$ \\
\hline LSPTV & $\begin{array}{l}\text { - Relatively insensitive to changing the feature } \\
\text { extraction rate } \\
\text { - Can provide accurate velocities in regions of } \\
\text { sparse surface features } \\
\text { - Works well in unsteady flows }\end{array}$ & $\begin{array}{l}\text { Relatively sensitive to changing the particle } \\
\text { identification area } \\
\text { - Additional post-processing is required for } \\
\text { optimum results } \\
\text { - Highly defined particle shapes need to be } \\
\text { defined [35] } \\
\text { Specific camera model is required in the } \\
\text { application before calculations can be } \\
\text { performed }\end{array}$ \\
\hline SSIV & $\begin{array}{l}\text { - Changing particle identification area does not } \\
\text { significantly affect the surface velocity results } \\
\text { - Standalone application (no parameters need } \\
\text { to be defined by the user) } \\
\text { - Works well in deteriorated image conditions } \\
\text { where shadows or glare are present on the } \\
\text { water surface }\end{array}$ & $\begin{array}{l}\text { - Small variations occur in results when feature } \\
\text { extraction rate is altered } \\
\text { - Specific camera model is required in the } \\
\text { application before calculations can be } \\
\text { performed }\end{array}$ \\
\hline
\end{tabular}

The conditions of sampling were designed to be ideal for LSPIV surveys; LSPIV has proven to be sensitive to varying seeding densities [27]. Therefore, seeding material was distributed continuously and homogeneously throughout the channel to reduce the uncertainty associated with seeding distributions. Furthermore, because of the particularly dark river background, the wood mulch provided a good contrast on the water surface. Therefore, particles could be identified more easily, 
allowing the cross-correlation algorithms to work effectively [10]. In areas whereby seeding particles are sparse or difficult to identify in subsequent frames, cross-correlation algorithms often struggle to accurately calculate the surface velocity [35]. Similar conditions also work well for all other algorithms, and typically surface features must be present for the detection of flow and accurate calculation of surface velocities [25]. However, seeding density is less crucial for accurate calculations when using LSPTV, SSIV, OTV or KLT-IV. Nevertheless, all algorithms underestimated the ADCP measurements towards the origin of the $x$-axis $(5 \mathrm{~m}$ ) (Figures 8 and 9). Due to the nature of the flow, seeding material was directed toward the center of the channel and the $x$-axis $(25 \mathrm{~m})$, thus seeding was sparse toward the origin of the $x$-axis ( $5 \mathrm{~m}$ ) (Figures 8 and 9). During field sampling, the river flow was very slow, and the background of the water surface was very dark, with only the seeding material as a visible moving feature on the waters' surface. Therefore, it is likely that toward the right bank ( $x$-axis $5 \mathrm{~m}$ ), where surface features were sparse, little or no water movement could be detected (Figures 8 and 9). Typically, all image velocimetry algorithms can only detect the flow if the human eye can observe the surface flow and in this scenario the flow is very difficult to detect toward the right bank ( $x$-axis $5 \mathrm{~m}$ ) (See Supplementary Materials).

Although the image velocimetry results are, on average, in good agreement with the ADCP measurements, it is likely that some factors are increasing the uncertainty in the results. Such factors include the stability of the images and the quality of the ADCP data. Before the image velocimetry analyses were conducted, images were stabilized through the KLT-IV algorithm. The mean stabilization error (RMSE) associated with the pre-processed data set was $1.27 \mathrm{px}$ on average, providing more stable frames than the original recorded images ( $33 \mathrm{px} /$ frame). In terms of its influence on the accuracy of surface velocity assessment, the magnitude of orthorectification error depends on the feature extraction rate and the image resolution. For example, a feature extraction rate of $2 \mathrm{fps}$ and a resolution of $0.01 \mathrm{~m}$, with an average stabilization error of $1.27 \mathrm{px}$, could lead to an average velocity error of $0.024 \mathrm{~m} \mathrm{~s}^{-1}$. This stabilization error may have contributed to some of the differences between the ADCP and image velocimetry measurements. Further research should be directed towards the assessment of the influence of stabilization errors on the accuracy of image velocimetry results.

During the low-energy conditions present during the experimental campaign, flow competence was minimal, with low concentrations of fine sediment $(<63 \mu \mathrm{m})$ present in the water column. This may lead to elevated levels of error and uncertainty related to error the ADCP reference measurements. For example, the acoustic backscatter signal of smaller suspended particles is of lower energy than that of larger ones, which negatively impacts the signal-to-noise ratio of the ADCP signal in low-velocity conditions [36]. This is in line with the conclusions of a USGS investigation, which states that the uncertainty of ADCP measurements increases with the decrease of flow velocity [33]. Thus, it is important to acknowledge a level of uncertainty within the ADCP dataset during the conditions presented. Nevertheless, image velocimetry measurements are generally in good agreement with the ADCP measurements, with differences of $0.05 \mathrm{~m} \mathrm{~s}^{-1}$, on average.

Notably, it is clear that the cross-section velocity profiles vary for the ADCP between the upstream cross-sections (S1 and S2) and the downstream cross-section (S3). The main reason for these differences, as described in the methodology, is a result of a dramatically changing bathymetry profile. Image velocimetry results for $\mathrm{S} 3$ are less consistent with the $\mathrm{ADCP}$ than those calculated at $\mathrm{S} 1$ and S2. Results presented highlight that at S3 all image velocimetry results overestimate the ADCP measurements across the majority of the transect. This is likely a result of a reduction in the depth causing surface velocities to increase, which is detected with higher accuracy with image velocimetry than the ADCP which relies on extrapolated data for the calculation of surface flow.

This experiment has demonstrated that during the conditions of sampling of slow flow with average surface velocities of $0.10-0.14 \mathrm{~m} \mathrm{~s}^{-1}$, image velocimetry techniques can reconstruct surface velocity profiles that are very similar to those calculated with an ADCP. As these techniques have proven to work well during low flows, the applications of image velocimetry could become much wider spread. The increased use of UAS within the environmental sciences has provided many 
new opportunities for remote monitoring methods [37]. For example, in river science applications, UAS have been used for quantifying river channel bathymetry [38], in-stream sediment sizes [39], bank erosion rates [40], mapping geomorphic features [41] and stream-flow measurements [15,20,25,42]. These developments have been facilitated by UAS becoming more affordable, commercially available and safer to fly. Therefore, in favourable conditions the use of UAS for quantifying flow rates using image velocimetry could aid a fully remote method for monitoring rivers. A particularly useful application for a remote method would be for assessing in-stream habitats. Habitat monitoring relies on a multitude of in-stream data to be collected over a high spatial resolution, including the surface velocity $[6,38]$. Different to traditional flow monitoring techniques such as ADCPs or current meters, image velocimetry applications have the benefit of collecting a high spatial resolution of surface velocity data over a very short time scale. A remote monitoring method could allow for a quicker, spatially continuous measurement to be conducted, without disturbing any habitats or bathymetry. One study has successfully measured surface flow velocity using LSPIV for aquatic habitat studies [6]. However, Smith et al. [6] used bankside cameras, and only focused on the LSPIV algorithm. This study has highlighted that UAS can also accurately calculate the surface flow velocity during low flow conditions, with a multitude of various algorithms.

\section{Conclusions}

This paper explores the sensitivity of five different algorithms to changing feature extraction rates and particle identification and search area/lengths. The low flow conditions tested within this study are considered challenging for image velocimetry; however, the aid of artificially added seeding material has aimed to overcome such challenges.

KLT and SSIV proved to be the least sensitive algorithms to changing the particle identification area (block size/IA), but experienced more variations in results when altering the feature extraction rate. On the other hand, OTV and LSPTV are more sensitive to changing the particle identification area (trajectory length/IA) than the feature extraction rate. For OTV a trajectory length of $2 \mathrm{~m}$ provided insufficient data for accurate comparisons, and thus this configuration was removed from the final analysis. LSPTV was the most sensitive algorithm in terms of the magnitude of velocity differences between the different configurations assessed, but only proved to be sensitive to changing the particle identification area. LSPIV, however, was the most sensitive algorithm to parametrization as changing both the feature extraction rate and particle identification and search areas created large variations in the surface velocities calculated between configurations. Overall, KLT, OTV, LSPIV and SSIV are in very good agreement with the ADCP measurements; however, OTV requires further validation upon the sensitivity of the trajectory length. Further experiments may be conducted using the entire length of each trajectory, rather than the midpoint used throughout this analysis. Furthermore, for all algorithms, future experiments should analyze the influence of pre- and post-processing procedures on the image velocimetry results calculated. For low flows, stabilization error should be kept as low as possible to reduce potential velocity errors as a result of an unstable platform.

One main advantage of KLT-IV and SSIV is the lack of user input required for the accurate calculation of surface velocity. With the KLT-IV application, little training is required and providing the camera model is listed within the application, then very few parameters need to be defined before the surface flow velocity can be calculated. Furthermore, SSIV is also implemented in the DischargeApp (discharge.ch) where no parameters related to the surface velocity calculation have to be introduced at all. This simplicity of use of KLT-IV and the DischargeApp overcomes the main current limitation with most image velocimetry algorithms. Some algorithms require additional effort for calibration and pre-processing. For example, with LSPIV and LSPTV, extensive training is required for an inexperienced user to define the appropriate parameters for an accurate surface flow velocity calculation. Furthermore, some algorithms, such as OTV, provided a limited description of the flow field, using the parameters defined throughout this study. 
During this experiment, a small section of laminar, slow flow conditions was assessed. Therefore, the results presented are limited to stable conditions. Further research may address the stability of image velocimetry algorithms during a range of flow conditions, including different flow rates and complexities of surface velocities (i.e., vortexes or highly turbulent flows). Furthermore, future research may assess a longer reach of river, in order to evaluate the capabilities of different algorithms in various morphological conditions that rivers possess. Future work may also focus on quantifying guidelines of which parameters should be used within different conditions (for example, different flow rates and geomorphological conditions) to improve the simplicity of applying image velocimetry techniques for non specialists.

Supplementary Materials: All Matlab scripts are now available at: https://github.com/sophie-pearce/ Sensitivity-Analysis-Belgrade. Additional supplementary materials are available from: https://drive.google. com/open?id=1zFp5v1qG-q9cFrMn27-ScQVBakTFC2HO.

Author Contributions: Conceptualization, S.M., S.P., R.L., S.P.-H., M.P., F.T., J.P. and D.P.; methodology, S.M., F.T., M.P., S.P., R.L., S.P.-H., D.S., S.F.D.S. and A.P.; software, M.P., F.T., S.P.-H.; validation, formal analysis, investigation and data curation, S.P., R.L., M.P., F.T., S.P.-H.; writing-original draft preparation, S.P., R.L. and M.P.; writing—review and editing, S.P., M.P., R.L., F.T., S.P.-H., D.S., I.M., S.G., A.P., S.F.D.S., S.M.; visualization, S.P., M.P. and R.L.; supervision, I.M., S.M., G.P.; project administration, S.M.; funding acquisition, S.M. and I.M. All authors have read and agreed to the published version of the manuscript.

Funding: This research was funded by the COST Action CA16219 "HARMONIOUS-Harmonization of UAS techniques for agricultural and natural ecosystems monitoring" and a University of Worcester funded PhD studentship.

Acknowledgments: The authors would like to thank the Department of Civil Engineering, Belgrade University for their assistance with field organization and data collection. With additional thanks to Antoine Patalano for the advice provided for the use of PTVlab. This work was partly supported by the Ministry of Education, Science and Technological Development of Serbia, grants TR37009 and TR37010.

Conflicts of Interest: The authors declare no conflict of interest.

\section{References}

1. Le Boursicaud, R.; Pénard, L.; Hauet, A.; Thollet, F.; Le Coz, J. Gauging extreme floods on YouTube: Application of LSPIV to home movies for the post-event determination of stream discharges. Hydrol. Process. 2016, 30, 90-105. [CrossRef]

2. Boiten, W.; Boiten, W. Hydrometry: IHE Delft Lecture Note Series; CRC Press: Boca Raton, FL, USA, 2008.

3. WMO. Manual on Stream Gauging, Volume II-Computation of Discharge; WMO: Geneva, Switzerland, 2010.

4. Costa, J.E.; Spicer, K.R.; Cheng, R.T.; Haeni, F.P.; Melcher, N.B.; Thurman, E.M.; Plant, W.J.; Keller, W.C. Measuring stream discharge by non-contact methods: A proof-of-concept experiment. Geophys. Res. Lett. 2000, 27, 553-556. [CrossRef]

5. Le Coz, J.; Hauet, A.; Pierrefeu, G.; Dramais, G.; Camenen, B. Performance of image-based velocimetry (LSPIV) applied to flash-flood discharge measurements in Mediterranean rivers. J. Hydrol. 2010, 394, 42-52. [CrossRef]

6. Smith, J.; Bérubé, F.; Bergeron, N. A field application of particle image velocimetry (PIV) for the measurement of surface flow velocities in aquatic habitat studies. In Proceedings of the 26th Canadian Symposium on Remote Sensing, Wolfville, NS, Canada, 14-16 June 2005.

7. Muste, M.; Hauet, A.; Fujita, I.; Legout, C.; Ho, H.C. Capabilities of large-scale particle image velocimetry to characterize shallow free-surface flows. Adv. Water Resour. 2014, 70, 160-171. [CrossRef]

8. Meselhe, E.; Peeva, T.; Muste, M. Large scale particle image velocimetry for low velocity and shallow water flows. J. Hydraul. Eng. 2004, 130, 937-940. [CrossRef]

9. Fujita, I.; Muste, M.; Kruger, A. Large-scale particle image velocimetry for flow analysis in hydraulic engineering applications. J. Hydraul. Res. 1998, 36, 397-414. [CrossRef]

10. Tauro, F.; Petroselli, A.; Arcangeletti, E. Assessment of drone-based surface flow observations. Hydrol. Process. 2015, 30, 1114-1130. [CrossRef]

11. Adrian, R.J. Particle-imaging techniques for experimental fluid mechanics. Annu. Rev. Fluid Mech. 1991, 23, 261-304. [CrossRef] 
12. Lewis, Q.W.; Rhoads, B.L. Resolving two-dimensional flow structure in rivers using large-scale particle image velocimetry: An example from a stream confluence. Water Resour. Res. 2015, 51, 7977-7994. [CrossRef]

13. Fujita, I.; Notoya, Y.; Furuta, T. Measurement of Inundating Flow from a Broken Enbankment by Using Video Images Shoot from a Media Helicopter. In Proceedings of the Ninth International Conference on Fluvial Hydraulics, Villeurbanne, France, 5-8 September 2018; Volume 40, p. 06001.

14. Le Coz, J.; Jodeau, M.; Hauet, A.; Marchand, B.; Le Boursicaud, R. Image-based velocity and discharge measurements in field and laboratory river engineering studies using the free Fudaa-LSPIV software. In Proceedings of the International Conference on Fluvial Hydraulics, RIVER FLOW, Lausanne, Switzerland, 3-5 September 2014; pp. 1961-1967.

15. Lewis, Q.W.; Lindroth, E.M.; Rhoads, B.L. Integrating unmanned aerial systems and LSPIV for rapid, cost-effective stream gauging. J. Hydrol. 2018, 560, 230-246. [CrossRef]

16. Dal Sasso, S.; Pizarro, A.; Samela, C.; Mita, L.; Manfreda, S. Exploring the optimal experimental setup for surface flow velocity measurements using PTV. Environ. Monit. Assess. 2018, 190, 460. [CrossRef]

17. Tauro, F.; Petroselli, A.; Porfiri, M.; Giandomenico, L.; Bernardi, G.; Mele, F.; Spina, D.; Grimaldi, S. A novel permanent gauge-cam station for surface-flow observations on the Tiber River. Geosci. Instrum. Methods Data Syst. 2016, 5, 241-251. [CrossRef]

18. Leitão, J.P.; Peña-Haro, S.; Lüthi, B.; Scheidegger, A.; de Vitry, M.M. Urban overland runoff velocity measurement with consumer-grade surveillance cameras and surface structure image velocimetry. J. Hydrol. 2018, 565, 791-804. [CrossRef]

19. Tauro, F.; Tosi, F.; Mattoccia, S.; Toth, E.; Piscopia, R.; Grimaldi, S. Optical tracking velocimetry (OTV): Leveraging optical flow and trajectory-based filtering for surface streamflow observations. Remote Sens. 2018, 10, 2010. [CrossRef]

20. Perks, M.T.; Russell, A.J.; Large, A.R.G. Technical Note: Advances in flash flood monitoring using unmanned aerial vehicles (UAVs). Hydrol. Earth Syst. Sci. 2016, 20, 4005-4015. [CrossRef]

21. Tsubaki, R.; Fujita, I.; Tsutsumi, S. Measurement of the flood discharge of a small-sized river using an existing digital video recording system. J. Hydro-Environ. Res. 2011, 5, 313-321. [CrossRef]

22. Kim, Y.; Muste, M.; Hauet, A.; Krajewski, W.F.; Kruger, A.; Bradley, A. Stream discharge using mobile large-scale particle image velocimetry: A proof of concept. Water Resour. Res. 2008, 44. [CrossRef]

23. Eltner, A.; Sardemann, H.; Grundmann, J. Flow velocity and discharge measurement in rivers using terrestrial and UAV imagery. Hydrol. Earth Syst. Sci. Discuss. 2019, 2019. [CrossRef]

24. Thielicke, W.; Stamhuis, E. PIVlab-Towards user-friendly, affordable and accurate digital particle image velocimetry in MATLAB. J. Open Res. Softw. 2014, 2. [CrossRef]

25. Tauro, F.; Petroselli, A.; Grimaldi, S. Optical sensing for stream flow observations: A review. J. Agric. Eng. 2018, 49, 199-206. [CrossRef]

26. Tauro, F.; Porfiri, M.; Grimaldi, S. Orienting the camera and firing lasers to enhance large scale particle image velocimetry for streamflow monitoring. Water Resour. Res. 2014, 50, 7470-7483. [CrossRef]

27. Muste, M.; Fujita, I.; Hauet, A. Large-scale particle image velocimetry for measurements in riverine environments. Water Resour. Res. 2008, 44. [CrossRef]

28. Sutarto, T.E. Application of large scale particle image velocimetry (LSPIV) to identify flow pattern in a channel. Procedia Eng. 2015, 125, 213-219. [CrossRef]

29. Weitbrecht, V.; Kühn, G.; Jirka, G. Large scale PIV-measurements at the surface of shallow water flows. Flow Meas. Instrum. 2002, 13, 237-245. [CrossRef]

30. Sontek. RiverSurveyor S5/M9-Discharge, Bathymetry and Current Profiling (brochure); Sontek: San Diego, CA, USA, 2015.

31. Morlock, S.E. Evaluation of acoustic Doppler current profiler measurements of river discharge. Water-Resour. Investig. Rep. 1996, 95, 4218.

32. Mueller, D.S.; Wagner, C.R.; Rehmel, M.S.; Oberg, K.A.; Rainville, F. Measuring Discharge with Acoustic Doppler Current Profilers from a Moving Boat; US Department of the Interior: Washington, DC, USA; US Geological Survey (EUA): Reston, VA, USA, 2009.

33. Blachard, S.F. Office of Surface Water Technical Memorandum 2005.05: Guidance on the Use of RD Instruments StreamPro Acoustic Doppler Profiler; Technical Report; U.S. Geological Survey: Reston, VA, USA, 2005.

34. Wolf, P.R.; Ghilani, C. Survey Measurement Adjustments by Least Squares. In The Surveying Handbook; Springer: Boston, MA, USA, 1995; pp. 383-413._16. [CrossRef] 
35. Tauro, F.; Piscopia, R.; Grimaldi, S. Streamflow observations from cameras: Large-scale particle image velocimetry or particle tracking velocimetry? Water Resour. Res. 2017, 53, 10374-10394. [CrossRef]

36. Gartner, J.W. Estimating suspended solids concentrations from backscatter intensity measured by acoustic Doppler current profiler in San Francisco Bay, California. Mar. Geol. 2004, 211, 169-187. [CrossRef]

37. Manfreda, S.; McCabe, M.F.; Miller, P.E.; Lucas, R.; Pajuelo Madrigal, V.; Mallinis, G.; Ben Dor, E.; Helman, D.; Estes, L.; Ciraolo, G.; et al. On the use of unmanned aerial systems for environmental monitoring. Remote Sens. 2018, 10, 641. [CrossRef]

38. Woodget, A.; Carbonneau, P.; Visser, F.; Maddock, I.P. Quantifying submerged fluvial topography using hyperspatial resolution UAS imagery and structure from motion photogrammetry. Earth Surf. Process. Landf. 2015, 40, 47-64. [CrossRef]

39. Woodget, A.; Fyffe, C.; Carbonneau, P. From manned to unmanned aircraft: Adapting airborne particle size mapping methodologies to the characteristics of sUAS and SfM. Earth Surf. Process. Landf. 2018, 43, 857-870. [CrossRef]

40. Marteau, B.; Vericat, D.; Gibbins, C.; Batalla, R.J.; Green, D.R. Application of Structure-from-Motion photogrammetry to river restoration. Earth Surf. Process. Landf. 2017, 42, 503-515. [CrossRef]

41. Langhammer, J.; Vacková, T. Detection and mapping of the geomorphic effects of flooding using UAV photogrammetry. Pure Appl. Geophys. 2018, 175, 3223-3245. [CrossRef]

42. Detert, M.; Weitbrecht, V. A low-cost airborne velocimetry system: Proof of concept. J. Hydraul. Res. 2015, 53, 532-539. [CrossRef]

(C) 2020 by the authors. Licensee MDPI, Basel, Switzerland. This article is an open access article distributed under the terms and conditions of the Creative Commons Attribution (CC BY) license (http:/ / creativecommons.org/licenses/by/4.0/). 